\title{
Nutrient Uptake in Huanglongbing-affected Sweet Orange: Transcriptomic and Physiological Analysis
}

\author{
Faisal Shahzad, Changpin Chun, Arnold Schumann, and Tripti Vashisth \\ University of Florida/Institute of Food and Agriculture Science, Citrus Research and Education \\ Center, 700 Experiment Station Road, Lake Alfred, FL 33850
}

Additional Index words. citrus greening, Citrus sinensis, fertilization, iron, manganese, tree defense response, zinc

\begin{abstract}
Since the advent of Huanglongbing [HLB (Candidatus Liberibacter asiaticus)] in Florida, several preliminary reports have emerged about the positive effects of mineral nutrition on the performance of HLB-affected citrus (Citrus sp.) trees. HLB-affected trees are known to undergo significant feeder root loss. Therefore, studies have focused on foliar nutrient application instead of soil-applied nutrients speculating that the HLB-affected trees root systems may not be competent in nutrient uptake. Some studies also suggest that HLB-affected trees benefit from micronutrients at higher than the recommended rates; however, the results are often inconclusive and inconsistent. To address this, the goal of the present study was to evaluate the nutrient uptake efficiency and the quantitative and qualitative differences in nutrient uptake of HLB-affected trees. HLB-affected and healthy sweet orange (Citrus sinensis) trees were grown in a $100 \%$ hydroponic system with Hoagland solution for 8 weeks. The trees were deprived of any fertilization for 6 months before the transfer of trees to the hydroponic solution. Altogether, the four treatments studied in the hydroponic system were healthy trees fertilized (HLY-F) and not fertilized (HLY-NF), and HLB-affected trees fertilized (HLB-F) and not fertilized (HLB-NF). HLY-F and HLY-NF trees were found to have similar levels of leaf nutrients except for $N$, which was found to be low in nonfertilized trees (HLY and HLB). Both HLB-F and HLB-NF trees had lower levels of Ca, Mg, and S compared with HLY trees. In addition, HLB-NF trees had significantly lower levels of micronutrients $\mathrm{Mn}, \mathrm{Zn}$, and Fe, compared with HLY-NF trees. The hydroponic solution analysis showed that HLB-F and HLY-F trees had similar uptake of all the nutrients. Considering that HLB-affected trees have a lower root-to-shoot ratio than healthy trees, nutrient uptake efficiency per kilogram of root tissue was significantly higher in HLB trees compared with HLY trees. Under nutrient-deficient conditions (day 0 ) only nine genes were differentially expressed in HLB roots compared with HLY roots. On the other hand, when fertilizer was supplied for $\approx 1$ week, $\approx 2300$ genes were differentially expressed in HLB-F roots compared with HLY-F roots. A large number of differentially expressed genes in HLB-F were related to ion transport, root growth and development, anatomic changes, cell death, and apoptosis compared with HLY-F trees. Overall, anatomic and transcriptomic analyses revealed that HLB-affected roots undergo remarkable changes on transitioning from no nutrients to a nutrient solution, possibly facilitating a high uptake of nutrients. Our results suggest the roots of HLB-affected trees are highly efficient in nutrient uptake; however, a small root mass is a major limitation in nutrient uptake. Certain micronutrients and secondary macronutrients are also metabolized (possibly involved in tree defense or oxidative stress response) at a higher rate in HLB-affected trees than healthy trees. Therefore, a constant supply of fertilizer at a slightly higher rate than what is recommended for micronutrients and secondary macronutrients would be beneficial for managing HLB-affected trees.
\end{abstract}

Currently, HLB affects $90 \%$ of commercial citrus (Citrus sp.) orchards (Singerman and Useche, 2016) and is the biggest challenge for the Florida citrus industry. With the epidemic of HLB, FL orange production has dropped by $\approx 70 \%$ (U.S. Department of Agriculture, 2019) in the past 15 years. HLB is a bacterial disease caused by the fastidious phloem-restricted bacterium Candidatus Liberibacter asiaticus (CLas). Once CLas is transmitted to a citrus tree, the sieve pores are plugged and phloem disruption is observed (Kim et al., 2009). The disruption of vascular function, loss of root mass, and altered mineral nutrition in CLas-infected trees lead to arrested tree and fruit growth, increased fruit drop, a decline in production, and could eventually lead to tree death (Bové, 2006; Halbert and Manjunath, 2004; Tang et al., 2019). Visible symptoms of HLB typically include yellowing of leaves, blotchy mottle, chlorotic patterns of

Received for publication 2 Apr. 2020. Accepted for publication 20 July 2020. Published online 18 September 2020.

This work is supported by State Legislative funding for the University of Florida/Institute of Food and Agriculture Science Citrus Initiative.

F.S. and C.C. contributed equally to the manuscript.

T.V. is the corresponding author. E-mail: tvashisth@uft.edu.

This is an open access article distributed under the CC BY-NC-ND license (https://creativecommons.org/licenses/by-nc-nd/4.0/). leaves resembling those induced by $\mathrm{Zn}$ and $\mathrm{Fe}$ deficiencies, shoot dieback, and reduced tree height (Bové, 2006).

There is no cure for HLB yet; therefore, citrus growers often face challenges for both replanting and managing their mature orchards. Several reports on the use of enhanced nutritional products to extend the vigor and productivity of HLB-affected trees by commercial citrus growers have been documented in the past several years (Spann and Schumann, 2012; Vashisth and Vincent, 2018). In a recent greenhouse study, HLB-affected sweet orange (C. sinensis) leaves had lower concentrations of $\mathrm{K}$, $\mathrm{Ca}, \mathrm{Mg}, \mathrm{Cu}, \mathrm{Fe}, \mathrm{Zn}, \mathrm{Mn}$, and $\mathrm{B}$ compared with leaves from healthy trees (Morgan et al., 2016). The same study also reported using three times the recommended rates of $\mathrm{Mn}$ and $\mathrm{Zn}$ (for healthy citrus by University of Florida) resulted in the improvement of health of HLB-affected trees (Morgan et al., 2016). Zambon et al. (2019) reported the therapeutic effects of high rates of Mn (three to four times higher than recommended rates) on CLas reduction in HLB-affected trees, thereby improving the productivity of HLB-affected sweet orange. Recently, in addition to enhanced fertilization, soil acidification for HLB-affected trees has become recommended. Irrigated Florida soil has a high $\mathrm{pH}$ due to high bicarbonate levels; this makes certain nutrients unavailable for uptake. Therefore, some citrus growers are opting 
for soil acidification and are observing improvement in yield and health of the trees (Morgan and Graham, 2019). Florida soil already had a high $\mathrm{pH}$ pre-HLB, but nutrient availability has become an issue since HLB's onset. Therefore, such field and scientific observations on nutrients, especially secondary macronutrients and micronutrients, raises a question about the nutrient uptake potential and nutrient requirement in HLB-affected trees. It is well known that HLB-affected trees undergo significant root loss on CLas infection (Graham et al., 2013). The feeder root dieback starts before visible symptoms appear on the canopy (Johnson et al., 2014). Overall, the root-to-shoot ratio decreases in HLB-affected trees. Hamido et al. (2017a, 2017b) showed that reduced water use and uptake in HLB-affected trees, but increasing the frequency of irrigation for HLB-affected trees can improve water uptake and use. Such findings raise numerous questions about feeder root performance and nutrient uptake efficiency in HLB-affected trees. To circumvent the impaired, HLB-affected roots for nutrient uptake many growers have switched to foliar nutrient application (Giles, 2011; Morgan et al., 2016). The nutrient uptake and required amount of nutrients in healthy citrus are well studied, where soil-application of all nutrients with supplemental foliar application of micronutrients is highly recommended (Obreza and Morgan, 2008). However, understanding nutrient uptake capacity and the potential of HLBaffected roots and if HLB-affected trees have a preferential uptake/requirement of certain nutrients is still lacking. Therefore, the objectives of this study were 1) to determine the nutrient uptake efficiency of HLB-affected trees, 2) to investigate the qualitative and quantitative differences in nutrient uptake among HLB-affected and healthy trees, and 3) to determine the molecular regulation of nutrient uptake in HLB-affected trees.

\section{Materials and Methods}

Tree material and experimental Design. Two-year old 'Midsweet' sweet orange budded on 'Kuharske Carrizo' citrange $(C$. sinensis $\times$ Poncirus trifoliata) rootstock potted (pot dimensions: $10.2 \times 10.2 \times 35.6 \mathrm{~cm}$ ) in commercial growing medium (mixture of peat/perlite/vermiculite at $3: 1: 1$ by volume) were used in this study. To obtain HLB-positive trees, the trees were budded with CLas-infected buds, whereas the healthy trees were mock-inoculated with healthy buds. Three months after inoculation, trees were confirmed for CLas infection by quantitative real-time polymerase chain reaction (qRT-PCR), as described by Vashisth and Livingston (2019). Uniform looking HLB-positive and healthy trees were selected and were kept in greenhouse for 6 months where they were not fertilized to create nutrient-deficient conditions. Throughout the experiment (including plant preparation time) the plants were grown under natural light conditions in the greenhouse; the temperature and relative humidity of the greenhouse fluctuated between 22 and $25{ }^{\circ} \mathrm{C}$ and $60 \%$ to $80 \%$, respectively. At the end of 6 months, both HLB-affected and healthy trees were transferred to a $100 \%$ hydroponic system [deionized (DI) water] with continuously running air pumps. Black 5-L buckets with lids were used for hydroponic setup. The lids of the buckets were cut out to fit the tree trunk and the trees were suspended in the buckets with help of a trellis. The experimental setup was a completely randomized block design $(n=4)$, where four trees were considered as one replicate. Trees were given 1 week for acclimatization to the hydroponic system before beginning the experiment. After 1 week, Hoagland solution (fertilizer) was added to a set of HLB-affected and healthy trees, whereas the other set of trees continued in the hydroponic system with no Hoagland solution (without fertilizer). Hoagland solution was prepared by mixing the reagents as follows: Group A (macronutrients): $5 \mathrm{~mm} \mathrm{Ca}\left(\mathrm{NO}_{3}\right)_{2} \cdot 4 \mathrm{H}_{2} \mathrm{O}, 5 \mathrm{~mm} \mathrm{KNO}$, $2 \mathrm{mM} \mathrm{MgSO}_{4} \cdot 7 \mathrm{H}_{2} \mathrm{O}$, and $1 \mathrm{mM} \mathrm{KH}_{2} \mathrm{PO}_{4}$; Group B (micronutrients): $46 \mu \mathrm{m} \mathrm{H} \mathrm{BO}_{3}, 9 \mu \mathrm{m} \mathrm{MnCl} \cdot 4 \mathrm{H}_{2} \mathrm{O}, 0.8 \mu \mathrm{m} \mathrm{ZnSO} \cdot 7 \mathrm{H}_{2} \mathrm{O}, 0.4 \mu \mathrm{m}$ $\mathrm{CuSO}_{4} \cdot 7 \mathrm{H}_{2} \mathrm{O}, 0.02 \mu \mathrm{m}\left(\mathrm{NH}_{4}\right)_{6} \mathrm{MoO}_{4} \cdot 4 \mathrm{H}_{2} \mathrm{O}, 0.02 \mu \mathrm{m} \mathrm{FeSO}_{4}$ $.7 \mathrm{H}_{2} \mathrm{O}$, and $0.02 \mu \mathrm{m}$ EDTA-Na $)_{2}$. Group A and B solutions were diluted 1:100 and 1:1000 (v:v), respectively, in the DI water. The water level was maintained at the 3.5-L mark in the bucket throughout the experiment (measured and replenished every $3 \mathrm{~d}$ ). The four treatments: 1) healthy trees with fertilizer solution (HLY-F), 2) HLB-affected trees with fertilizer solution (HLB-F), 3) healthy trees without fertilizer solution (HLY-NF), and 4) HLB-affected trees without fertilizer solution (HLB-NF) were evaluated for the following variables during the course of 8 weeks.

Tree biomass AND GROwTH. Trees were destructively harvested and leaf, shoot, and root fresh and dry weights were measured at the end of the experiment. Dry weight was measured by drying the samples at $68^{\circ} \mathrm{C}$ for $\approx 72 \mathrm{~h}$ in a convection oven (Thermo Fisher Scientific, Waltham, MA). Increase in the number of leaves, tree height, and stem diameter was determined by calculating the difference from the time of adding fertilizer solution (day 0 ) to the end of the experiment and is expressed as a percentage change. Leaf chlorophyll index (SPAD value) was measured for five same-age leaves on days $0,7,14,28,42$, and 56 using a chlorophyll concentration meter (MC-100; Apogee Instruments, Logan, UT).

Physical, Chemical, AND NUTRIENT PROFILE OF GROWING MEDIA AND LEAVES. A digital $\mathrm{pH} /$ conductivity meter (Orion Star A215; Thermo Fisher Scientific) was used to measure the $\mathrm{pH}$ and electrical conductivity (EC) (millisiemens per centimeter) of the hydroponic solution on days $0,7,14,28,42$, and 56 of the experiment.

On days 0,28 , and $56,20-\mathrm{mL}$ samples of the hydroponic solutions were collected. Leaves were collected at the end of the experiment and were washed using $1 \%(\mathrm{v} / \mathrm{v})$ anionic detergent (Liqui-Nox; AlcoNox, White Plains, NY), rinsed with DI water, followed by drying at $68^{\circ} \mathrm{C}$ for $48 \mathrm{~h}$, and then were milled using a grinder (Fex IKA A11; IKA-Werke, Staufen, Germany). The ground leaf and hydroponic solution samples were sent to Waters Agricultural Laboratories (Camilla, GA) to perform a standard nutrient analysis. Based on the nutrient concentration in the hydroponic solution, the nutrient uptake efficiency of roots (milligrams nutrient per kilogram of root) was calculated for HLB-F and HLY-F trees using the formula:

$\begin{aligned} \text { nutrient uptake efficiency }= & {[\text { mineral nutrient concentration }} \\ & (\text { milligrams per liter }) \text { in } \\ & \text { hydroponic solution on day } \\ & 0 \text { - mineral nutrient concentration } \\ & (\text { milligrams per liter }) \text { in } \\ & \text { hydroponic solution on day 56) } \\ & \times 3.5 \mathrm{~L}] / \text { fresh root biomass } \\ & (\text { kilograms })\end{aligned}$

RooT ANALYSIS. At the end of the experiment, feeder roots of HLB-F and HLY-F trees were categorized in new and old 
growth. Different root variables such as length, diameter, volume, and surface area were calculated using WinRHIZO software (version 2012b; Regent Instruments, Quebec City, QC, Canada).

For anatomic analysis, $\approx 0.5-\mathrm{cm}$-long feeder roots were collected at five different locations from the root system on days 0 and 14 . Root samples were fixed in a 50\% ethyl alcohol, $10 \%$ formalin, and $5 \%$ acetic acid solution and stored at $4{ }^{\circ} \mathrm{C}$ until further analysis. Paraffin protocol was followed from Ruzin (1999) with slight modifications. Briefly, samples were rinsed in DI water with graded series of ethanol, embedded in paraffin, and sectioned $(10 \mu \mathrm{m})$ using a microtome. After removal of paraffin from the sections, Toluidine Blue $(0.1 \%$ of aqueous solution) was used for staining. Samples were analyzed under a charge-coupled device digital camera (Omax 14.0 MP; Olympus, Tokyo, Japan) attached to an epifluorescence microscope (BX61; Olympus). Image analysis was done using ImageJ software (National Institutes of Health, Bethesda, MD) (Schindelin et al., 2012).

Transcriptome ANALysis. Transcriptome analysis was performed on two treatments: HLY-F and HLB-F. Feeder roots were collected from the same order of roots on days 0,3 , and 9 . The root samples were immediately flash frozen in liquid nitrogen and stored in $-80{ }^{\circ} \mathrm{C}$ until further analysis. Total RNA was extracted from $100 \mathrm{mg}$ of root samples using modified TRIzol protocol (Chomczynski and Sacchi, 1987). The quantity and quality of extracted RNA were evaluated using a spectrophotometer (Epoch 2 Microplate; BioTek Instruments, Winooski, VT) and denaturing formaldehyde 1.2\% agarose gels (Rio, 2015), respectively. For global transcriptome analysis using RNA sequencing (RNAseq), the samples were sent to the Interdisciplinary Center for Biotechnology Research, University of Florida (Gainesville). The illumina TruSeq mRNA protocol (Illumina, San Diego, CA) was used for the transcript sequencing. The $C$. sinensis genome v1.1 (Wu et al., 2014) from the Phytozome database was used as a reference genome for transcript sequencing. Differential gene expression (DEG) was analyzed using RSEM v1.2.31 (Li and Dewey, 2011) with a cutoff of the absolute value of $\log _{2}$ fold change (LFC) greater than 1. A false discovery rate (FDR)corrected probability value of less than or equal to 0.05 was used as the threshold. It should be noted that the DEGs presented in the current study were significantly upregulated or downregulated in HLB-F roots compared with HLY-F roots.

Multiple tools were used to study the biological significance from the results of RNAseq. MapMan software [version 3.5.1.R2 (Thimm et al., 2004; Usadel et al., 2005)] was used to identify the biochemical or physiological processes represented by DEGs; the percentage of DEGs in each functional category (BIN) is reported over total number of DEGs. To get statistically significant $(P<0.05)$ and nonredundant gene ontology (GO) terms for individual upregulated and downregulated DEGs, gene sets from treatments at each time points were annotated using AgriGO in tandem with REVIGO (Supek et al., 2011;
Tian et al., 2017), respectively. In addition, the enzymes encoded by DEGs involved in the metabolic pathways were determined by using the Kyoto Encyclopedia of Genes and Genomes (KEGG) Mapper tool (Kanehisa et al., 2017).

RELATIVE GENE EXPRESSION ANALYSIS. To validate the results of RNAseq analysis, qRT-PCR was used to determine the relative expression of eight selected genes including senescence-associated gene 20 (SAG20), ethylene response factor 1 (ERF1), calcium dependent calmodulin (CAM8), 2-oxoglutarate and $\mathrm{Fe}$ dependent oxygenase superfamily protein (OG-FE), auxin-responsive family protein (ABF3), and zinc transporter 10 precursor (ZIP10). The two normalization genes used were actin $(A C T)$ and DIM1 homolog/YLS8 (DIM). Complementary DNA synthesis, qRT-PCR reaction, and gene expression calculations were done as described in Vashisth and Livingston (2020). List of genes, GenBank accession number, and primers used are presented in Supplemental Table 1.

Statistical analysis. All the data were analyzed using a one-way or two-way analysis of variance in Sigma Plot (version 12; Systat Software, San Jose, CA). Mean separation among treatments was performed using Tukey's honestly significant test at $\alpha \leq 0.05$.

This experiment was conducted twice to validate the findings; however, the transcriptomic and anatomical analysis was performed only on the second experiment due to limited resources. The greenhouse and nutrient analysis results of the two experiments were similar; thus, the results presented herein are from the second experiment.

\section{Results}

\section{Tree biomass and growth}

At the end of the experiment, both HLB-F and HLB-NF trees had significantly lower total biomass as well as individual root, shoot, and leaf biomass compared with HLY-F and HLY-NF trees (Table 1). The root, shoot, and leaf biomass were not different among HLB-F and HLB-NF or HLY-F and HLY-NF trees. HLY-F trees had the highest increase in leaf number and HLB-F, HLB-NF, and HLY-NF had the similar increase. There was no significant increase in the growth of fertilized (both HLB and HLY) trees compared with nonfertilized trees (both HLB and HLY; Table 1). At the beginning of the experiment, HLB-affected trees showed a 30\% lower SPAD value compared with healthy trees (Fig. 1). The SPAD value for HLY-F

Table 1. Growth parameters of Huanglongbing (HLB)-affected and healthy (HLY) sweet orange trees grown in hydroponic solution with fertilizer (F) and no-fertilizer (NF) for $56 \mathrm{~d}$.

\begin{tabular}{lccccc}
\hline Parameter & HLB-F & HLY-F & HLB-NF & HLY-NF & $P$ value \\
\hline Fresh root biomass $(\mathrm{g})^{\mathrm{z}}$ & $11.2 \mathrm{~b}^{\mathrm{y}}$ & $24.3 \mathrm{a}$ & $13.3 \mathrm{~b}$ & $22.7 \mathrm{a}$ & 0.001 \\
Fresh shoot biomass $(\mathrm{g})$ & $15.9 \mathrm{~b}$ & $25.1 \mathrm{a}$ & $17.3 \mathrm{~b}$ & $23 \mathrm{a}$ & 0.007 \\
Fresh leaf biomass $(\mathrm{g})$ & $6.5 \mathrm{~b}$ & $15.1 \mathrm{a}$ & $7 \mathrm{~b}$ & $9 \mathrm{a}$ & 0.040 \\
Fresh whole tree biomass $(\mathrm{g})_{\text {Change in number of leaves }^{\mathrm{x}}}^{33.6 \mathrm{~b}}$ & $64.4 \mathrm{a}$ & $37.7 \mathrm{~b}$ & $54.7 \mathrm{a}$ & 0.002 \\
Increase in tree height $(\%)^{\text {Increase in stem diameter (\%) }}$ & $18.9 \mathrm{~b}$ & $22.5 \mathrm{a}$ & $11.2 \mathrm{~b}$ & $12.3 \mathrm{~b}$ & 0.005 \\
& 10.5 & 12.3 & 7.4 & 8.1 & NS \\
\hline
\end{tabular}

${ }^{\mathrm{z}}$ Fresh root biomass, fresh shoot biomass, fresh leaf biomass, and fresh whole tree biomass are absolute values measured at the end of experiment ( $56 \mathrm{~d}$ ).

${ }^{\mathrm{y}}$ Means followed by different letters indicate statistically significant differences among different treatments for given parameter using Tukey's honestly significant difference test at $\alpha=0.05$.

${ }^{\mathrm{x}}$ Number of leaves, increase in tree height, and increase in stem diameter are calculated by considering the difference in measurement between day 56 and day 0 . 


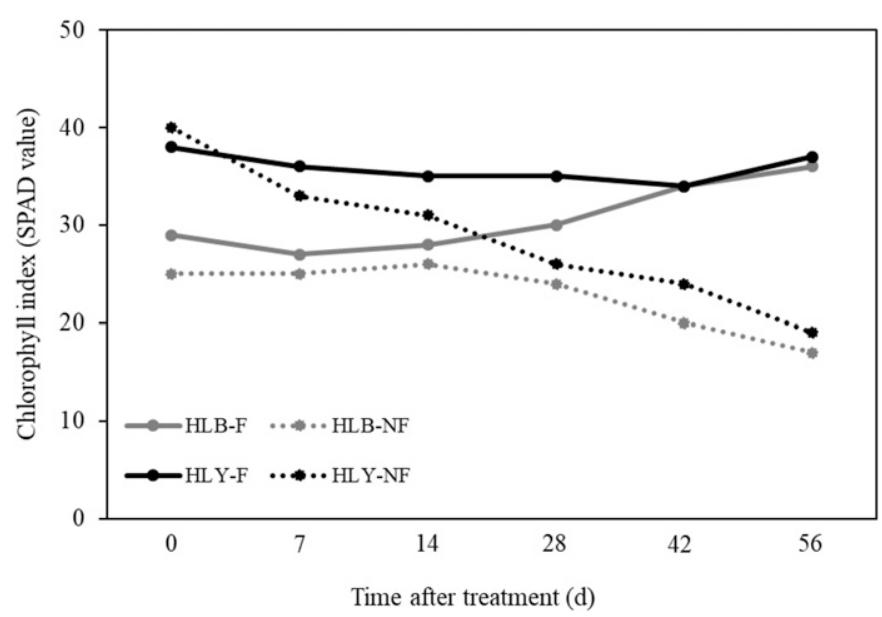

Fig. 1. Average leaf chlorophyll index expressed as SPAD value for Huanglongbing (HLB)-affected and healthy (HLY) sweet orange trees grown under fertilized (F) and nonfertilized (NF) hydroponic conditions during the course of experiment (from day 0 to 56). Before day 0 both HLB and HLY plants were grown in nutrient-deficient conditions for 6 months.

did not change during the experiment but increased in HLB-F trees over 8 weeks. HLB-F and HLY-F had same SPAD value at the end of the experiment. The SPAD value of HLB-NF and HLY-NF decreased by $24 \%$ and $43 \%$, respectively, from the start until the end of the experiment.

\section{Physical, chemical, and nutrient profile of growing medium and leaves}

No significant differences were found in the $\mathrm{pH}$ of the hydroponic solution of HLB and HLY trees (F and NF) at the end of the experiment (data not shown). EC decreased by $40 \%$ during the experiment as the fertilizer depleted from the hydroponic solution; 2.06 and $2.08 \mathrm{mS} \cdot \mathrm{cm}^{-1}$ to 1.25 and 1.27 $\mathrm{mS} \cdot \mathrm{cm}^{-1}$ in HLB-F and HLY-F, respectively.

No significant difference was observed in water use among HLB-F and HLY-F trees. There was also no difference in water use for HLB-NF and HLY-NF trees; however, the water use in HLB-F and HLY-F trees was significantly higher than HLB-NF and HLY-NF trees, respectively. Mineral nutrient analysis of the hydroponic solution was performed on days 0,28 , and 56 to determine the quantitative and qualitative differences in the nutrient uptake of HLB-F and HLY-F trees; all the nutrients in HLB-F and HLY-F trees were at the same concentration on day 0 of the experiment. Overall, the nutrient concentrations decreased in the hydroponic solution of both HLB-F and HLY-F as the experiment progressed, suggesting nutrient uptake by the trees. At the end of the experiment, all nutrients in the HLB-F and HLY-F growing media solutions were at similar concentrations. Interestingly, on day 28 , the $\mathrm{P}$ uptake in HLB-F trees was lower than in HLY-F trees as suggested by the $\mathrm{P}$ concentration in the hydroponic solution (Supplemental Fig. 1), although it was similar on day 56. Manganese and $\mathrm{Fe}$ concentrations in the hydroponic solution of both HLB-F and HLY-F trees decreased abruptly by day 28 and on day 56 very little $\left(<0.05 \mathrm{mg} \cdot \mathrm{L}^{-1}\right)$ was found, suggesting a rapid uptake of these nutrients by the trees.

At the end of the experiment, the nutrient analysis of the leaves showed that HLB-NF trees had a significantly lower concentration for most of the nutrients as compared with HLY-
NF (Fig. 2). In HLY-F and HLY-NF, the concentration for 9 of 10 nutrients was the same. HLY-NF trees had lower $\mathrm{N}$ concentrations than HLY-F; a similar trend was seen for HLB-F and HLB-NF trees. Overall, the nutrient concentrations in HLB-F trees and HLY-F trees were equivalent except for the secondary macronutrients $\mathrm{Ca}, \mathrm{Mg}$, and $\mathrm{S}$, where a significant effect on tree health (disease) was seen. Both HLB-F and HLB$\mathrm{NF}$ trees were lower in $\mathrm{Ca}, \mathrm{Mg}$, and $\mathrm{S}$ than HLY-F and HLY-NF trees. A significant interaction between tree health and fertilization was observed in $\mathrm{K}, \mathrm{Mn}, \mathrm{Fe}$, and $\mathrm{Zn}$, where HLB-NF trees had lower concentrations of the respective nutrients than HLB-F, HLY-F, and HLY-NF trees. No significant differences were found in $\mathrm{P}$ and $\mathrm{B}$ concentrations in HLB-F, HLB-NF, HLY-F, and HLY-NF trees.

At the end of the experiment, nutrient uptake efficiency was calculated as milligram of nutrient per kilogram of root tissue in both HLB-F and HLY-F. On average, HLB-F trees had 2- to 3-fold higher $(P<0.05)$ nutrient uptake efficiency for both macro- and micronutrients than HLY-F trees (Fig. 3). The concentrations of all the nutrients in the hydroponic solution of HLB-F and HLY-F trees were similar at the end of the experiment, which reinforces the nutrient uptake efficiency results.

\section{Root analysis}

HLB-F trees had a lower average feeder root diameter ( $\leq 2 \mathrm{~mm}$ ), root volume, and root length than HLY-F trees (Table 2), but no significant difference was observed in the root diameter and volume of new feeder root growth in HLB-F and HLY-F. However, the length of newly grown feeder roots in HLB-F trees was significantly shorter than new growth in HLYF. Old feeder roots of HLB-F were lower in diameter, volume, and length than HLY-F roots. According to an ImageJ analysis for day 0, HLB-F root had a lower vascular bundle diameter and a lower ratio of vascular bundles to root diameter $(0.28)$ than HLY-F trees (0.39) (Fig. 4). Both HLB-F and HLY-F roots showed an increase in vascular bundle diameter when grown under the fertilizer condition. An increase was observed in the ratio of vascular bundles to root diameter of 1.7-fold in HLB-F and 1.4-fold in HLY-F on day 14 compared with day 0 . The mean diameter of vascular bundles and vascular bundles to the diameter ratio was significantly higher in HLY-F trees than HLB-F trees on day 14 (Fig. 4), although when the increase in the ratio of vascular bundle to diameter between days 0 and 14 was evaluated, the increase in HLB-F trees was significantly higher than HLY-F trees.

\section{Transcriptomic analysis}

A total of 9, 19, and 2324 DEGs were expressed in HLB-F and HLY-F roots on days 0,3 , and 9, respectively (Table 3). Notably, all 9 DEGs in HLB-affected roots were upregulated on day 0. In HLB-F trees, 5 and 14 DEGs were upregulated and downregulated on day 3, respectively. On day 9, 627 and 1697 DEGs were upregulated and downregulated in HLB-F, respectively, compared with HLY-F roots.

Due to a small number of DEGs in HLB-F and HLY-F roots on days 0 and 3, an enrichment analysis (either via MapMan or GO) could not be performed. Gene names with description and LFC of the nine DEGs in HLB-F roots on day 0 are presented in Table 4.

An overview comparing the metabolic processes of HLB-F roots and HLY-F roots on day 9 was obtained using the MapMan enrichment analysis (Fig. 5). The BINs that included 

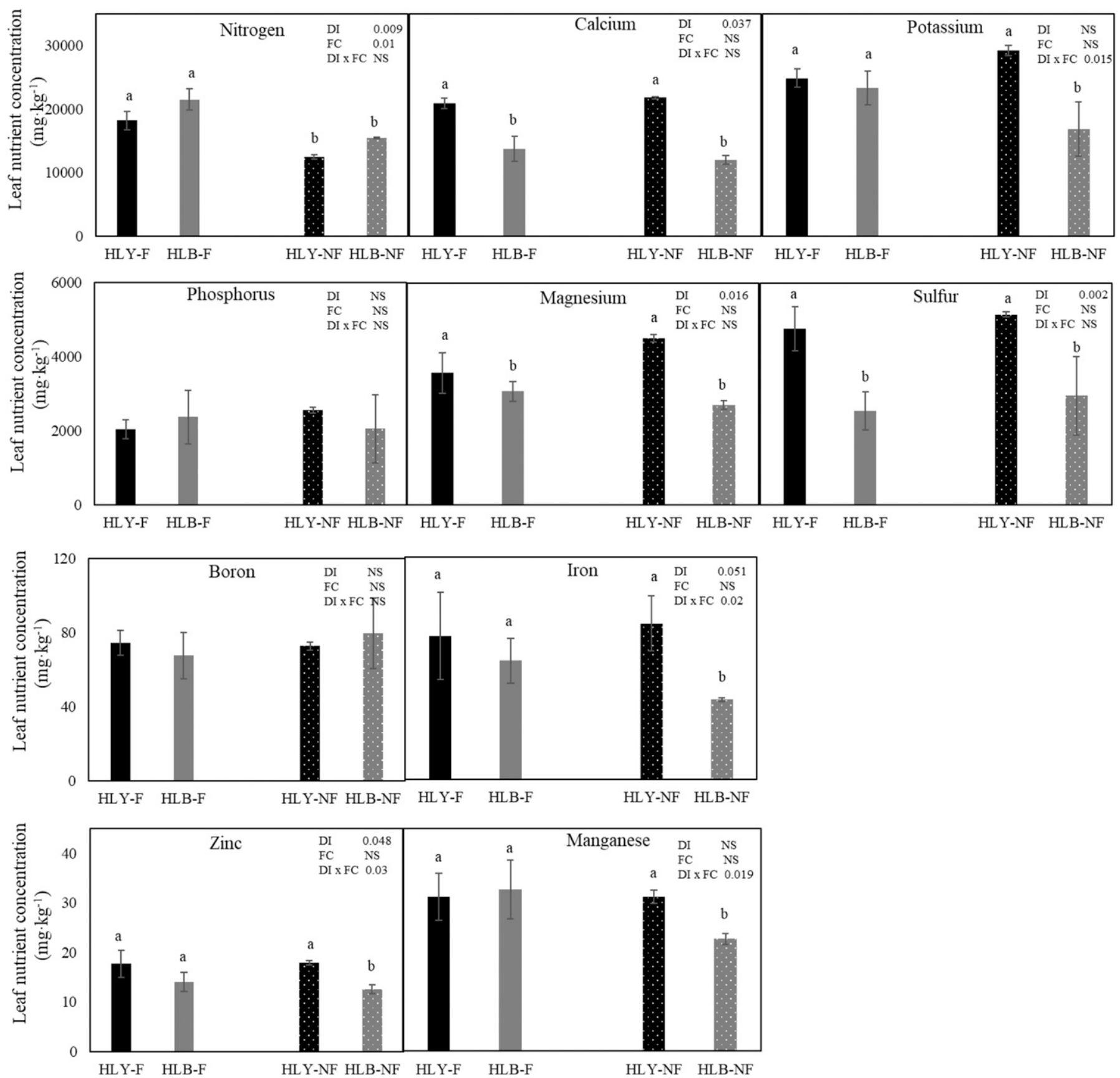

Fig. 2. Leaf mineral nutrient content of sweet orange trees with two disease indexes \{DI [Huanglongbing (HLB)-affected and healthy (HLY)]\} grown in hydroponic media of two fertilizer conditions $\{\mathrm{FC}$ [fertilized (F) and nonfertilized conditions (NF)] for $56 \mathrm{~d}$. Before addition of fertilizer, both HLB and HLY trees were grown in nutrient-deficient conditions for 6 months. Different letters in each panel indicate significant difference based on Tukey's honestly significant difference test $(\alpha=0.05)$; NS $=$ not significantly different.

more than $2 \%$ DEGs were BIN 35 with no assigned functions (29\% DEGs), followed by protein (BIN 29;12\% DEGs), RNA (BIN 27; 11\% DEGs), signaling (BIN 30; $9 \%$ DEGs), stress (BIN 20;5\% DEGs), transport (BIN 34;5\% DEGs), cell (BIN 31; 5\% DEGs), DNA (BIN 28; 5\% DEGs), development (BIN 33; 3\% DEGs), hormone metabolism (BIN 17; $2 \%$ DEGs), and secondary metabolism (BIN 16; $\%$ DEGs). On day 9, GO enrichment analysis was performed using upregulated and downregulated DEGs in HLB-F roots compared with HLY-F roots (Fig. 6). For the upregulated DEGs in HLB-F, the top 10 biological enriched GO categories were related to transport, cellular amino acid and derivative metabolic process, oxoacid metabolic process, organic acid biosynthesis processes, phenylpropanoid metabolic process, response to carbohydrate stimulus, ethylene and the jasmonic acid-mediated signaling pathway, and regulation of hormone levels. The top enriched GO categories based on the downregulated DEGs were the developmental process, phosphate metabolic process, protein modification process, defense response, growth, cell cycle, cell death, and abscisic 

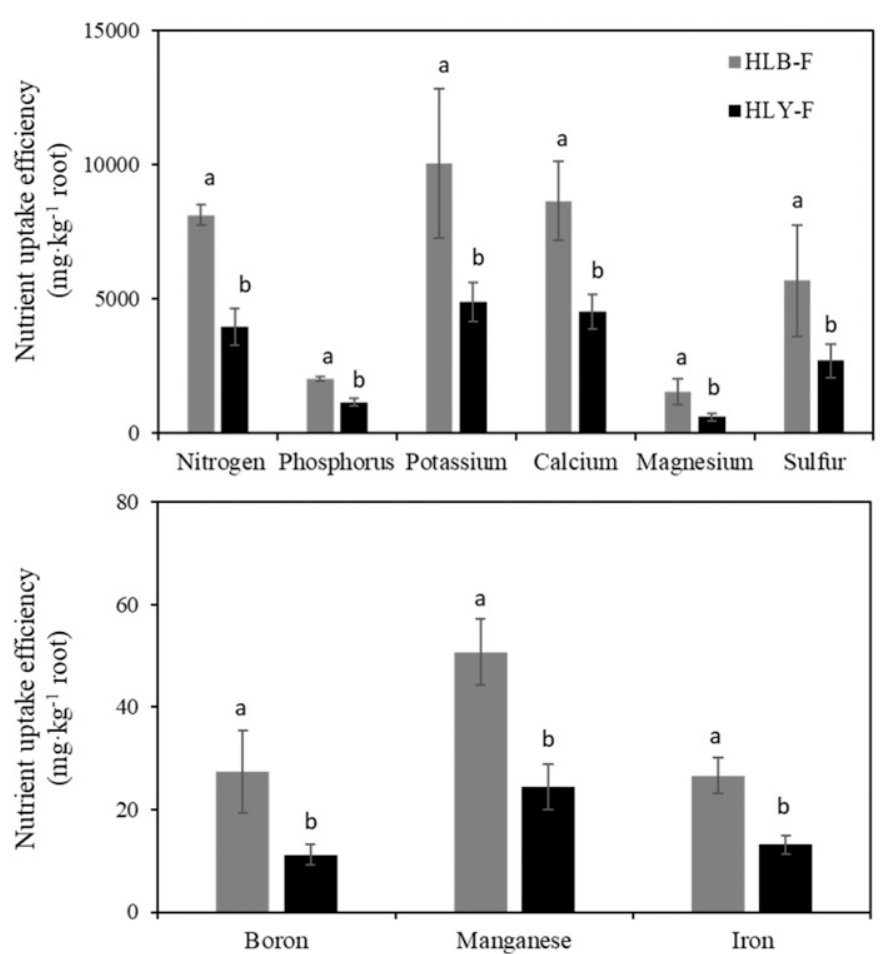

Fig. 3. Root nutrient uptake efficiency of Huanglongbing (HLB)-affected and healthy (HLY) sweet orange trees grown in hydroponic system with fertilizer (F) for $56 \mathrm{~d}$. Different letters above each bar for each nutrient indicate significant difference between roots of HLB-affected and healthy trees based on Tukey's honestly significant difference test $(\alpha=0.05)$.

Table 2. Feeder root analysis of Huanglongbing (HLB)-affected and healthy (HLY) sweet orange trees grown with fertilizer $(\mathrm{F})$ for $56 \mathrm{~d}$.

\begin{tabular}{lrcc}
\hline Root characteristic & HLB-F & HLY-F & $P$ value \\
\hline Total feeder roots & & & \\
$\quad$ Root length $(\mathrm{cm})$ & $614.8 \mathrm{~b}^{\mathrm{z}}$ & $1551.6 \mathrm{a}$ & 0.023 \\
Average diameter $(\mathrm{cm})$ & $1.47 \mathrm{~b}$ & $1.95 \mathrm{a}$ & 0.036 \\
Root volume $\left(\mathrm{cm}^{3}\right)$ & $2.49 \mathrm{~b}$ & $6.02 \mathrm{a}$ & 0.036 \\
New feeder roots & & & \\
Root length $(\mathrm{cm})$ & $47.4 \mathrm{~b}$ & $139.5 \mathrm{a}$ & 0.037 \\
Average diameter $(\mathrm{cm})$ & 0.73 & 0.65 & NS \\
Root volume $\left(\mathrm{cm}^{3}\right)$ & 0.23 & 0.47 & NS \\
Old feeder roots & & & \\
Root length $\left(\mathrm{cm}^{3}\right)$ & $567.3 \mathrm{~b}$ & $1412.1 \mathrm{a}$ & 0.032 \\
Average diameter $(\mathrm{cm})$ & $0.74 \mathrm{~b}$ & $1.29 \mathrm{a}$ & 0.014 \\
Root volume $\left(\mathrm{cm}^{3}\right)$ & $2.27 \mathrm{~b}$ & $5.55 \mathrm{a}$ & 0.045
\end{tabular}

${ }^{\mathrm{z}}$ Means followed by different letters indicate statistically significant differences among different treatment combinations using Tukey's honestly significant difference test at $\alpha=0.05$.

acid (ABA)-mediated signaling pathway. Five GO categories: metabolic process, response to stimulus, cellular nitrogen compound metabolic process, response to stress, and response to abiotic stress included both upregulated and downregulated DEGs. In all these GO groups, most of the genes were downregulated in HLB-F roots compared with HLY-F roots.

DEGS RELATED TO NUTRIENT TRANSPORT. A total of 65 DEGs related to transport were upregulated in HLB-F roots as compared with HLY-F roots; 20 of 65 DEGs were related to ion transport (GO:0006811) (Table 5). Similarly, the MapMan analysis showed $5 \%$ of DEGs were related to transport. Most upregulated DEGs were involved in cation transport such as $\mathrm{NH}_{4}{ }^{+}, \mathrm{K}, \mathrm{N}, \mathrm{Zn}, \mathrm{Fe}$, and $\mathrm{Cu}$. Notably, $\mathrm{Zn}$ ion transport had the highest LFC (5.23) in this group. Upregulated DEGs that were involved in anion transport include $\mathrm{PO}_{4}{ }^{3-}, \mathrm{B}, \mathrm{Cl}^{-}$, and $\mathrm{S}$ transport. All 13 DEGs related to response in nutrient level (GO:0031667) were found to be upregulated in HLB-F roots compared with HLY-F (Table 5). In addition, a group of 115 DEGs belonging to the phosphate metabolic process (GO:0006796) were downregulated in HLB-F roots but not in HLY-F roots.

DEGs RELATED TO HORMONES. Based on the enriched GO categories and MapMan analysis, 33 DEGs were involved in hormone regulation and 2\% DEGs in BIN 17 (hormone metabolism), respectively. Upregulated DEGs were related to hormonal regulation (GO:0010817), the jasmonic acid-mediated signaling pathway (GO:0009867), and the ethylene-mediated signaling pathway (GO:0009873). All the DEGs related to the ABA-mediated signaling pathway (GO:0009738) were downregulated in HLB-affected trees vs. healthy trees. These enriched GO category results agree with the outcome of MapMan: most DEGs involved in ABA (BIN 17.1), brassinosteroids (BIN 17.3), auxin (BIN 17.2), and salicylic acid (BIN 17.8) were downregulated (Fig. 6; Supplemental Tables 2 and 3). Whereas DEGs related to ethylene (BIN 17.5) and gibberellic acid (GA) (BIN 17.6) were upregulated in HLB-F roots compared with HLY-F roots (Fig. 7). Cytokinin (BIN 17.4) included one upregulated DEG and two downregulated DEGs.

DEGS RELATED TO STRESS, TREE-PATHOGEN/PEST INTERACTION, DEFENSE RESPONSE, AND SECONDARY METABOLISM. In HLB-F roots compared with HLY-F roots, 66 DEGs upregulated and 158 DEGs were downregulated, in response to stress (GO:0006950) (Fig. 6). Based on the results from the MapMan analysis, $5 \%$ of DEGs were related to BIN 20 (stress) (Fig. 5). In addition, treepathogen/pest interaction was highly enriched in HLB-F roots compared with HLY-F roots (Fig. 7; Supplemental Tables 3 and 4). The DEGs were related to ABA (BIN 17.1), auxin (BIN 17.2), brassinosteroids (BIN 17.3), glutathione $\mathrm{S}$ transferase (BIN 26.9), R-stress biotic receptors (BIN 20.1.2), peroxidases (BIN 26.12), WRKY transcription factors (BIN 27.3), cell wall biotic stress (BIN 10.5, 10.7 and 10.8), jasmonate (17.7.1), ethylene (17.5), pathogenesis-related (PR) proteins (BIN 20.1.7), salicylic acid (BIN 17.8.1), and MYB family protein (BIN 27.3.25) (Supplemental Table 3). Another highly affected category in tree-pathogen interactions was redox reactions. The associated DEGs were dismutase and catalase (BIN 21.6), redox thioredoxin (BIN 21.1), protein degradation (BIN 29.5), glutathione ascorbate (BIN 21.2.1), and glutaredoxin family proteins (BIN 21.4), suggesting that HLB-F trees were undergoing processes to mitigate oxidative stress. Fifty-five DEGs related to the GO term tree defense response (GO:0006952) were found to be downregulated in HLB-F roots compared with HLY-F roots. Fourteen DEGs related to the phenylpropanoid biosynthesis process were upregulated in HLB-F roots compared with HLY-F roots (Supplemental Fig. 2). An analysis via KEGG showed that the proteins encoded by 14 DEGs belonged to the phenylpropanoids process and lignin biosynthesis. Upregulated DEGs in the phenylpropanoid biosynthesis pathway were related to the genes that encoded phenylalanine ammonia lyase [PAL (EC 4.3.1.5)], hydroxycinnamoyl-coenzyme a shikimate:quinate hydroxycinnamoyl-transferase [HCT (EC 3.1.1)], caffeic acid/5-hydroxyferulic acid O-methyltransferase 


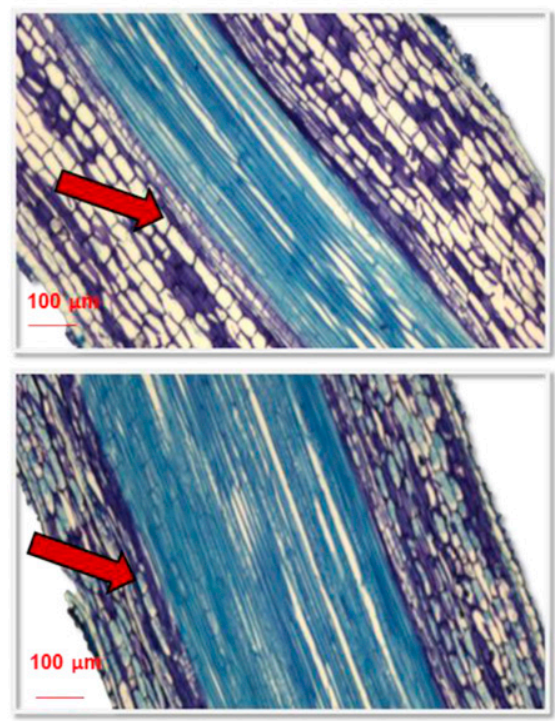

After 14 d with fertilizer solution

HLB trees

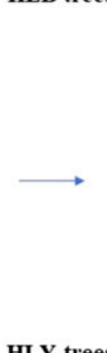

HLY trees
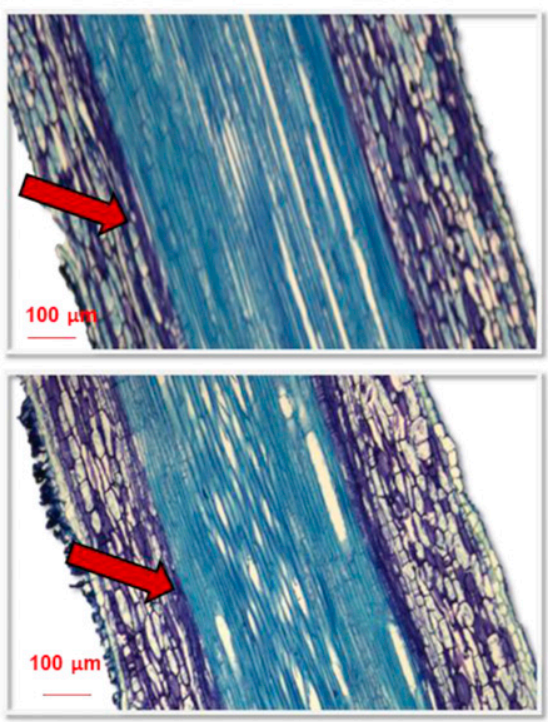

Fig. 4. Longitudinal sections showing comparative anatomical changes in vascular bundles in feeder root of Huanglongbing (HLB)-affected and healthy (HLY) sweet orange trees at the start of experiment (day 0 ) and after $14 \mathrm{~d}$ after the addition of fertilizer $(\mathrm{F})$ to hydroponic system. Before day 0 both HLB and HLY trees were grown in nutrient-deficient conditions for 6 months. Red arrow points at the difference in the vascular bundle diameter between days 0 and 14 .

Table 3. Total number of differentially expressed genes (DEGs) among Huanglongbing (HLB)affected and healthy (HLY) sweet orange trees grown in fertilizer solution (F) on days 0,3 , and 9 after the addition of Hoagland solution (fertilizer) to the hydroponic system. Before day 0 both HLB and HLY plants were grown in nutrient-deficient conditions for 6 months.

\begin{tabular}{lrrr}
\hline Comparison & DEGs & Upregulated DEGs & Downregulated DEGs \\
\hline HLB-F vs. HLY-F day 0 & 9 & 9 & 0 \\
HLB-F vs. HLY-F day 3 & 19 & 5 & 14 \\
HLB-F vs. HLY-F day 9 & 2324 & 627 & 1697 \\
HLB-F day 0 vs. d 3 & 8 & 8 & 0 \\
HLB-F day 0 vs. d 9 & 23 & 7 & 16 \\
HLB-F day 3 vs. d 9 & 57 & 31 & 26 \\
HLY-F day 0 vs. d 3 & 1339 & 583 & 756 \\
HLY-F day 0 vs. d 9 & 1659 & 773 & 886 \\
HLY-F day 3 vs. d 9 & 2426 & 1241 & 1185 \\
\hline
\end{tabular}

[COMT (EC 2.1.1.68)], ferulate 5hydroxylase $(\mathrm{F} 5 \mathrm{H})$, cinnamyl alcohol dehydrogenase [CAD (EC 11.1.195)], and peroxidases [POD (EC 1.11.1.7)].

DEGS RELATED TO DEVELOPMENT AND DEATH. This super GO group included four distinct GO terms: developmental process (GO:0032502), growth (GO:0040007), cell cycle (GO:0007049), and cell death (GO:0008219). The super group had 269 DEGs, which were all downregulated (Fig. 6) in HLB-F roots compared with HLY-F roots.

\section{Relative gene expression}

Gene expression and RNAseq results were found to be in agreement $(P=0.015, r=0.76)$. A significant interaction effect between tree disease condition and days after treatment was found on the expression of $S A G 20, E R F 1$, $C A M 8, O G-F e, A B F 3$, and ZIP10 in HLB-F and HLY-F roots (Fig. 8). $S A G 20$ expression was significantly downregulated in HLB-F roots compared with HLY roots at day 0 ; on day $9 S A G 20$ was upregulated in HLB-F roots resulting in similar expressions between HLB$\mathrm{F}$ and HLY-F. On day $0, E R F 1$ and $C A M 8$ in both HLB-F and HLY-F had similar expressions; however, on day 9 HLY-F roots showed significant downregulation of both genes but HLB-F remained the same. On the other hand, in $O G$ $F e$ and $A B F 3$, both genes were equally expressed on day 0 . On day 9 the expression in HLB-F roots was significantly downregulated for both genes. In ZIP10, no

Table 4. List of nine differentially expressed genes in Huanglongbing (HLB)-affected sweet orange trees in comparison with healthy sweet orange trees on day 0 along with their orange gene IDs, $\log _{2}$ fold change (LFC), and Arabidopsis homologs. Day 0 is the time point just before the addition of Hoagland solution (fertilizer) to the hydroponic system. Before day 0, both HLB and HLY plants were grown in nutrientdeficient conditions for 6 months.

\begin{tabular}{llll}
\hline Gene & LFC & Arabidopsis homologs & \multicolumn{1}{c}{ Description } \\
\hline orange1.1g014036m & 2.07 & AT3G51670.1 & Phosphoglyceride transfer family protein \\
orange1.1g025435m & 2.91 & AT5G62720.1 & Integral membrane HPP family protein \\
orange1.1g031858m & 3.33 & AT3G15680.1 & Ran BP2/NZF zinc finger-like superfamily protein \\
orange1.1g030361m & 3.57 & AT1G69700.1 & HVA22 homologue C \\
orange1.1g033664m & 3.84 & AT5G22580.1 & Stress responsive A/B Barrel Domain \\
orange1.1g020451m & 4.76 & AT1G49570.1 & Peroxidase superfamily protein \\
orange1.1g018585m & 6.14 & AT1G31260.1 & Zinc transporter 10 precursor \\
orange1.1g046055m & 6.44 & AT1G75820.1 & Leucine-rich receptor-like protein kinase family protein \\
orange1.1g032726m & 7.76 & & Strictosidine synthase-related sub family/biosynthesis of \\
& & & terpenoid indole alkaloids present in meristematic tissue \\
\hline
\end{tabular}




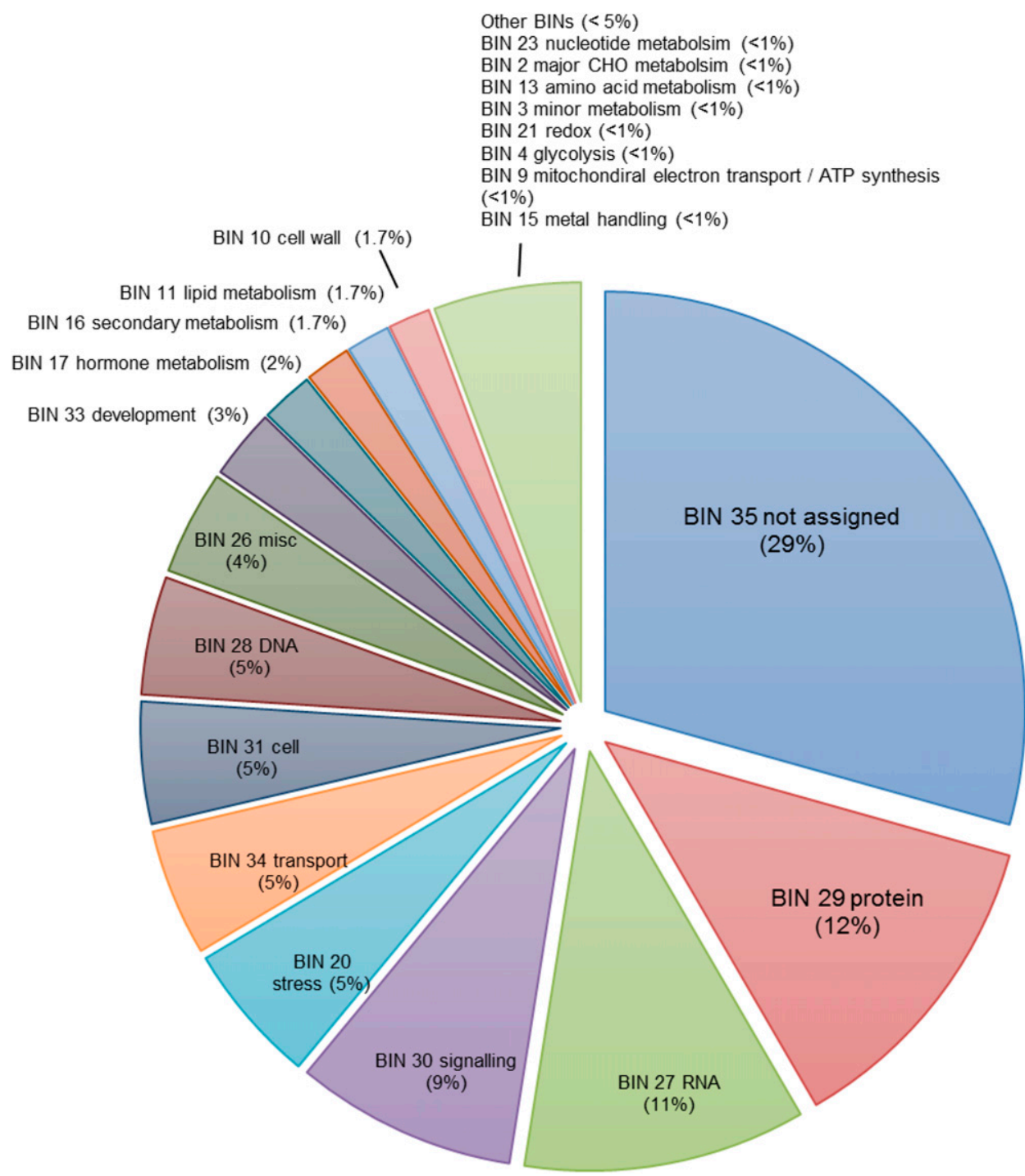

Fig. 5. Functional categories (BINs) of differentially expressed genes (DEGs) using MapMan enrichment analysis (Thimm et al., 2004; Usadel et al., 2005) in Huanglongbing (HLB)-affected and healthy (HLY) sweet orange trees at day 9 since the addition of fertilizer to the hydroponic system. Before day 0 both HLB and HLY trees were grown in nutrient-deficient conditions for 6 months.

expression was detected in HLY-F and HLB-F roots on day 0 and the expression increased on day 9. The increase in expression of ZIP10 was significantly higher in HLB-F roots as compared with HLY-F roots.

\section{Discussion}

In this study, HLB-affected trees had lower biomass for root, shoot, and leaf compared with healthy trees. HLB-affected trees (F and NF) notably had $\approx 40 \%$ to $50 \%$ less root biomass compared with HLY trees (F and NF); the reduction in shoot and leaf biomass was not as prominent in HLB-affected trees. Feeder root length, diameter, and volume were higher in HLY$F$ trees than HLB-F trees, depicting higher root decline and mortality in HLB-affected trees (Johnson et al., 2014). The root microscopy analysis of HLB-F trees showed that vascular bundle diameter was less when trees were deprived of fertilizer, suggesting severe implications for survival on roots. Overall, the effect of HLB is more pronounced on roots as compared with the shoot system (Graham et al., 2013; Johnson et al., 2014).

During the experiment, the trees were grown with fertilizer for $\approx 2$ months; the tree height and stem diameter were measured to estimate the growth of the trees at the end of experiment. No significant increases in tree height or stem diameter were observed among HLB (both F and NF) and HLY (both F and NF). Similarly, the tree biomass measured at the end of the experiment was not different for HLB-F and HLB-NF trees and HLY-F and HLY-NF trees, suggesting that the effect of fertilization on growth was not observed in the short term (Zekri and Koo, 1991). Often researchers do not see improvement in growth or yield of HLB-affected trees in only 1 to 2 years of HLB-nutrition research (Gottwald et al., 2012; Rouse et al., 2017; Vashisth, 2020). This suggests that HLB-nutrition research, like healthy citrus research, should be conducted for longer durations to appropriately evaluate the treatments, particularly with large, mature trees.

HLB-affected trees are well documented to have a low leaf chlorophyll content compared with healthy trees due to massive starch accumulation (Schneider, 1968) that occurs in chloroplasts and physically disrupts thylakoid structure (Sasek et al., 1985; Yelle et al., 1989). Both HLY and HLB trees in this study were grown in nutrient-deprived conditions for 6 months before the hydroponic and fertilizer treatments. At day 0 the SPAD value of HLB-affected (F and NF) trees were significantly lower than HLY (F and NF) trees. However, when the HLB-F trees were given a nutrient solution, the leaf chlorophyll content significantly increased; at the end of the experiment, HLB-F and HLY-F trees had a similar leaf chlorophyll index. These observations suggest that good fertilization could improve the leaf chlorophyll index which then improves the photosynthetic capacity (Krause and Weis, 1991) of HLBaffected trees.

At the end of the experiment, all nutrients except $\mathrm{N}$, were at similar levels among healthy trees (F and NF). Nitrogen was the only nutrient that was affected by the fertilizer condition of both HLB and HLY trees. On the other hand, when HLB-NF trees were compared with HLY-NF, the leaf nutrient content of $\mathrm{Ca}, \mathrm{Mg}, \mathrm{S}, \mathrm{K}, \mathrm{Mn}, \mathrm{Fe}$, and $\mathrm{Zn}$ were lower in HLB-NF trees, suggesting that HLB-NF trees were metabolizing these nutrients at a higher rate than HLY-NF trees. Manganese, Zn, and $\mathrm{Fe}$ are well known to be involved in the enzymatic process of reactive oxygen species (ROS) control and the sequestration 
Day 9 HLB vs. HLY

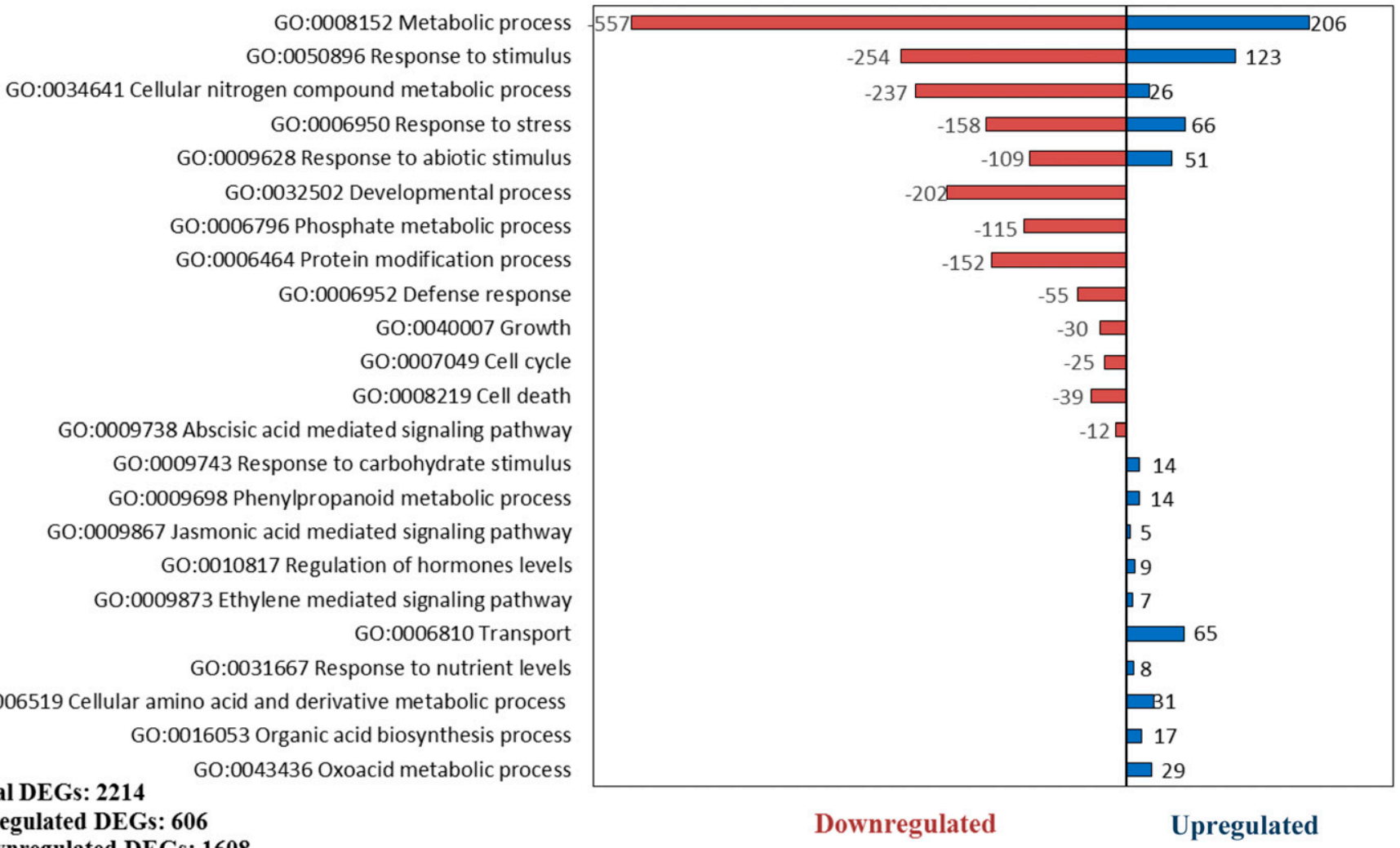

Upregulated DEGs: 606

Downregulated DEGs: 1608

Downregulated Upregulated

Fig. 6. Gene ontology (GO) classification of upregulated and downregulated differentially expressed genes (DEGs) in Huanglongbing (HLB)-affected and healthy (HLY) sweet orange trees at day 9 since the addition of fertilizer to the hydroponic system. Before day 0 both HLB and HLY trees were grown in nutrient-deficient conditions for 6 months. Blue and orange colors represent the number of upregulated and downregulated DEGs, respectively, in roots of HLB-affected compared with healthy trees.

process, thereby mitigating the deleterious effects of the disease (Romheld and Marschner, 1991). HLB-affected trees go through excessive oxidative stress as a result of infection. The tree then undergoes a significant number of processes to suppress or sequester ROS and counteract the effects of oxidative stress (Martinelli et al., 2012; Tang and Vashisth, 2020). Hence, it is likely that in these reactions micronutrients are used at a higher rate to mitigate disease effects; this implies that the fertilization practices should change for HLBaffected trees compared with healthy trees. This is supported by reports of Morgan et al. (2016), Vashisth (2020), and Zambon et al. (2019), in which higher than the recommended rtes of micronutrients were beneficial for HLB-affected trees. Another noticeable finding is that when nutrients were available HLB-F trees accumulated the same amount of nutrients as HLY-F trees except for the secondary macronutrients $\mathrm{Ca}, \mathrm{Mg}$, and $\mathrm{S}$, which were lower in HLB- affected (F and NF) trees than in HLY (F and NF). This observation sheds light on two points: 1) $\mathrm{Mg}, \mathrm{Ca}$, and $\mathrm{S}$ concentrations are affected by disease conditions. These nutrients are possibly metabolized at a higher rate in HLB-affected trees. It has been reported that $\mathrm{S}$ is involved in tree defense responses (Capaldi et al., 2015) and imparts antifungal and antibacterial properties to the tree. Magnesium and $\mathrm{Ca}$ are also known to reduce oxidative damage and contribute to antioxidant properties (Cakmak and Marschner, 1992; Pandey et al., 2015). Thus, it is possible that HLB-affected trees, which are in a constant state of elevated tree defense response and oxidative stress, require these nutrients at higher rates than healthy citrus. 2) Even though HLB-NF trees had significantly lower leaf nutrient concentrations for 8 of 10 nutrients, HLB-F trees were low in only three nutrients under nutrient-available conditions compared with HLY-F. This suggests that the performance of HLB-affected trees can be elevated on fertilization (Morgan et al., 2016) as the nutrients are taken up by the trees and are accumulated in the leaves.

The nutrient accumulation results are also supported by EC and the nutrient analysis of the hydroponic solution conducted in this study. All the nutrient concentrations and EC of the hydroponic solution were the same at the start of the experiment (addition of Hoagland solution) as well as at the end, suggesting that the nutrient uptake was the same in HLB-F and HLY-F trees. It is worth noting that HLB-affected trees have significantly lower root and leaf biomass compared with healthy trees. Therefore, when the nutrient uptake efficiency of all the nutrients was calculated, HLB-F trees had a nutrient uptake efficiency 2- to 3-fold higher than HLY-F trees. This indicates that the HLB-F root system has a better nutrient uptake capacity than the HLY-F root system. HLB-affected trees are known to have compromised root systems so many growers have switched to foliar fertilization practices (Giles, 2011), assuming that the compromised roots of HLB-affected trees are not 
Table 5. Differentially expressed genes belonging to gene ontology (GO) term ion transport (GO:0006811) and response to nutrients levels (GO:0031667) with respective orange gene IDs, Arabidopsis homologs, and $\log _{2}$ fold change (LFC) in Huanglongbing (HLB)-affected sweet orange trees in comparison with healthy sweet orange trees on day 9 since the addition of Hoagland solution (fertilizer).

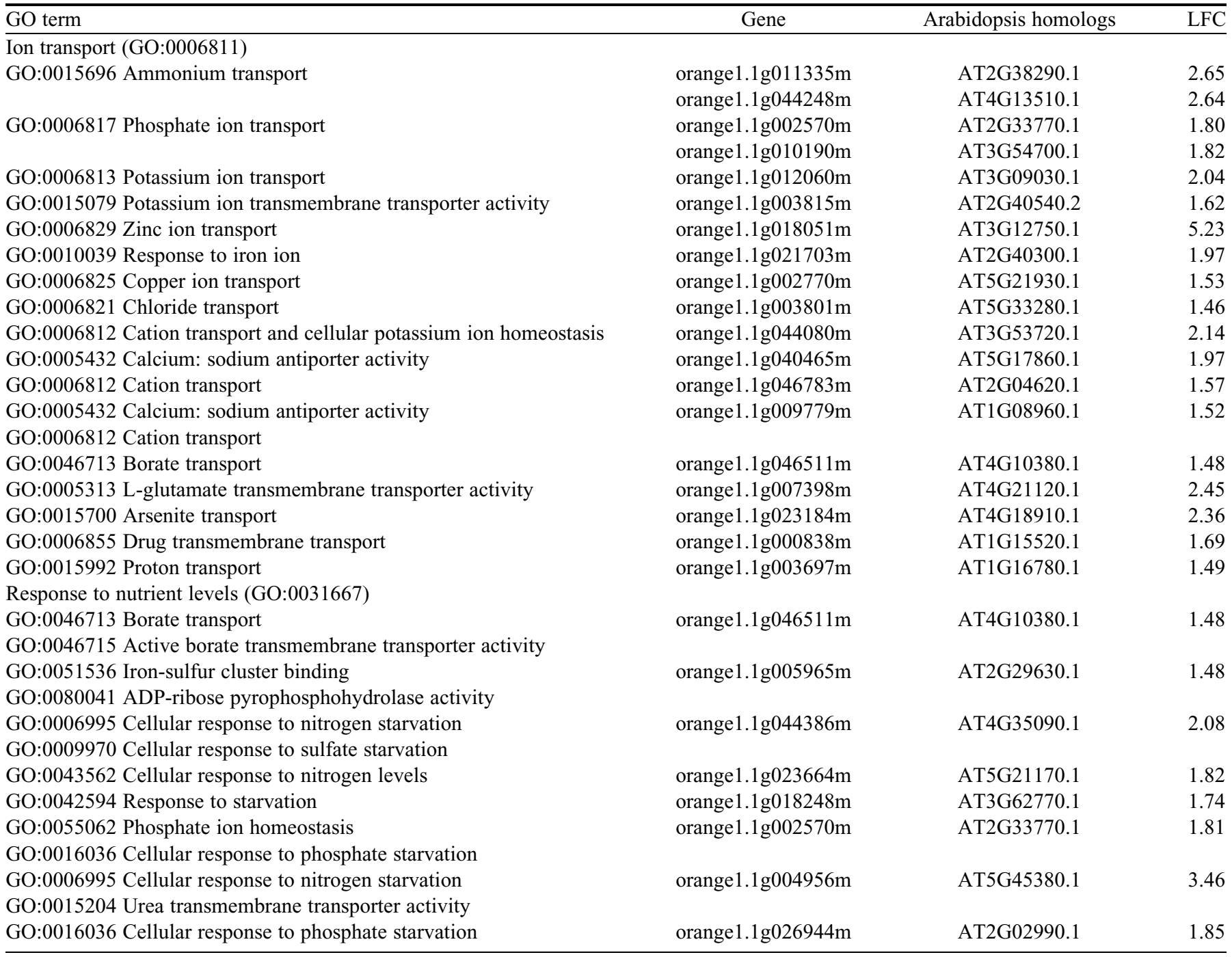

efficient in nutrient uptake. Presented findings suggest that HLB-affected root systems can take up nutrients efficiently but a small root system may limit the uptake of the total amount of nutrients. Due to the imbalance in the reduction of root-to-shoot ratio, the roots need to increase their uptake efficiency, possibly by going through a rapid turnover and reduced longevity of feeder roots (Johnson and Graham, 2015). It is also likely that the significant increase in the vascular bundle to root diameter ratio that was observed in the HLB-affected roots from day 0 to 14 improves the nutrient uptake efficiency of the HLB-affected roots.

The transcriptome analysis performed on HLB-affected and healthy trees on days 0,3 , and 9 supports the greenhouse data. Under no-fertilizer condition (day 0), only 9 DEGs were expressed in HLB-affected trees, all of which were upregulated. This is also consistent with gene expression analysis where all the genes except $S A G 20$ were expressed equally among HLB-F and HLY-F on day 0 . Both HLB-affected trees and healthy trees were undergoing the same kind of nutrient-deficient stress; however, HLB-affected trees were undergoing additional biotic stress due to the bacterial disease. When healthy and HLBaffected trees are compared, as is the case here, it is typically unlikely to find such a small number of DEGs (Martinelli et al., 2012); therefore, it is possible that both types of trees were probably undergoing similar metabolic processes to cope during the 6 months of the fertilizer deficient conditions. However, the nine upregulated DEGs found in the HLB-F trees possibly play a critical role in the tree's response to disease, especially under nutrient-deficient conditions. Among these genes, the LFC of strictocidine synthase (orange1.1g032726) was 7.74 in HLB-F roots compared with HLY-F roots. Strictosidine synthase is the key enzyme for the synthesis of camptothecin, which is an alkaloid known to be involved in biotic and abiotic stress response of plants (Isah, 2019; Kusari et al., 2012). Another DEG, zinc transporters 10 precursor (ZIP10, orange1.1g018585), was upregulated by 6.14 LFC in HLB-F roots. ZIP 10 is involved in transporting the cations $\mathrm{Zn}, \mathrm{Fe}, \mathrm{Mn}$, and $\mathrm{Cu}$ (Lin et al., 2009). Notably, $\mathrm{Zn}$ transporter family proteins are linked with the defense against oxidative stress (Guerinot and Eide, 1999). Trees depend on Zn-regulated 


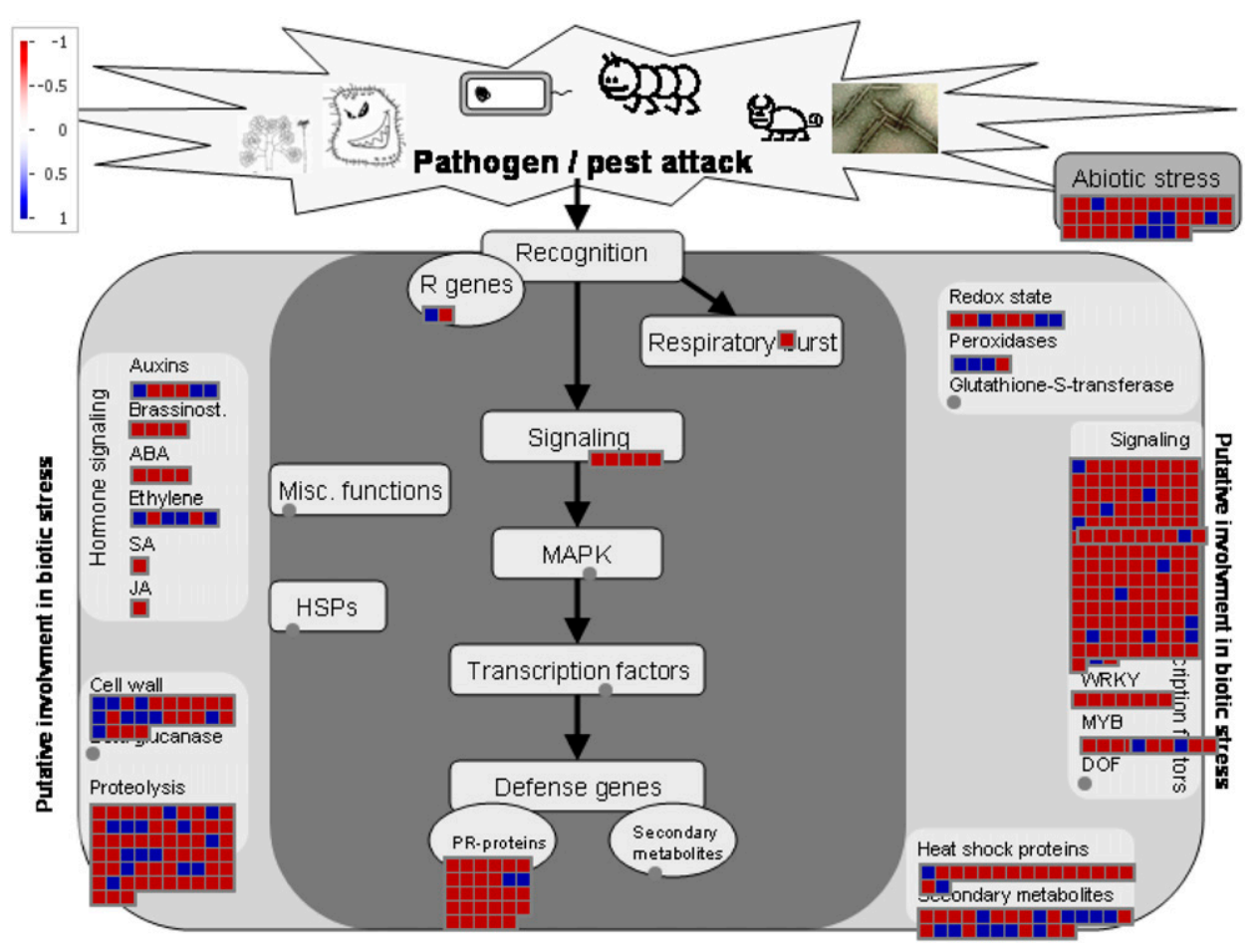

Fig. 7. Visualization of functional categories (BINs) of differentially expressed genes (DEGs), using MapMan (Thimm et al., 2004; Usadel et al., 2005), relating to plant pathogen/pest interaction Huanglongbing (HLB)affected and healthy (HLY) sweet orange trees at day 9 since the addition of fertilizer to the hydroponic system. Before day 0 both HLB and HLY trees were grown in nutrient-deficient conditions for 6 months. This particular process includes BINs related to hormones, redox reactions, defense genes, signaling, heat shock proteins, and biotic stress. transporters, Fe-regulated transporter (IRT)-like protein (ZIP), and natural resistance-associated macrophage protein families to maintain ion homeostasis (Hall and Guerinot, 2006). In this study, HLB-NF trees were found to be deficient in $\mathrm{Mn}$, $\mathrm{Zn}$, and Fe, suggesting that HLBaffected trees under nutritiondeprived conditions metabolize these nutrients at a higher rate than healthy trees. Because of this, the roots were possibly expressing ZIP10 actively to uptake these critical micronutrients for survival. Gene expression results showing that ZIP10 was significantly upregulated in HLB-F roots on day 9 compared with HLY-F support this possibility as well. The other DEGs that were upregulated in HLB-F trees on day 0 were leucine-rich repeat receptor-like kinases, which have a role in tree growth, morphogenesis, tree defense, and disease resistance (Becraft, 2002; de Lorenzo et al., 2009; Greeff et al., 2012; Tör et al., 2009); peroxidase superfamily protein is involved in oxidative stress (Gaspar et al., 1992); stress responsive $a / b$ barrel domain and ran $b p 2$
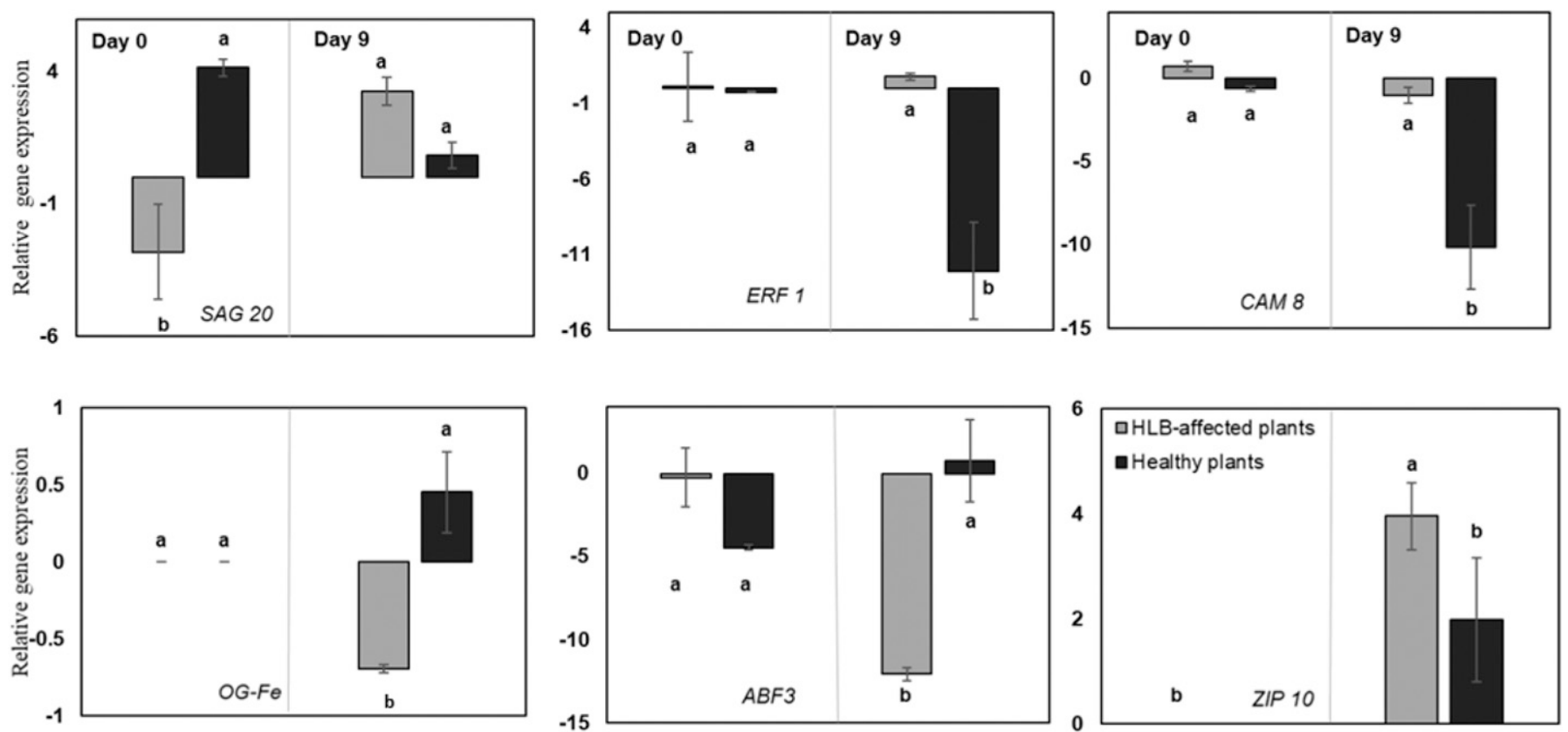

Fig. 8. Relative gene expression ( $\log _{2}$ fold change) of senescence associated gene 20 (SAG20), ethylene response factor 1 (ERF1), calcium dependent calmodulin (CAM8), 2-oxoglutarate and Fe dependent oxygenase superfamily protein (OG-Fe), auxin-responsive family protein (ABF3), zinc transporter 10 precursor (ZIP10) in roots of Huanglongbing (HLB)-affected and healthy (HLY) sweet orange trees on day 0 and 9 since the addition of fertilizer to the hydroponic system. Before day 0, both HLB and HLY trees were grown in nutrient-deficient conditions for 6 months. Data are means \pm SD of three biological replicates. Different letters in each panel indicate significant difference among each other based on Tukey's honestly significant difference test $(\alpha=0.05)$. NS $=$ not significantly different. 
nzf figure like super family protein are involved in salicylic acid pathways (Wiermer et al., 2005); hva22 homologue is a unique stress-induced protein that acts as a negative regulator for GAmediated programmed cell death; phosphoglyceride transfer family protein and integral membrane hpp family protein involved in nitrate response in Arabidopsis thaliana, which induces the genes in nitrate transport, nitrate reduction, ammonium assimilation, and generation of NADPH through oxidative phosphate pathway (Scheible et al., 2004). It should be noted that the greenhouse results showed that nitrogen was deficient in both HLB-NF and HLY-NF trees.

On day 9, 2324 DEGs were observed in HLB-F roots compared with HLY-F roots, of which 627 genes were upregulated and 1697 were downregulated. It is worth pointing out that the DEGs in HLB-F and HLY-F between days 0 (no nutrient) and 9 (growing for $9 \mathrm{~d}$ in the nutrient) increased by $\approx 2300$ genes; however, the increase was gradual because on day 3 only 19 DEGs were present. On day 9 all the GO categories except five were exclusively downregulated or upregulated. The two most enriched categories were "response to stress" and "abiotic stress." Both categories had a high number of downregulated genes in HLB-F roots; fewer than one-third of the genes were upregulated. The GO category response to abiotic stress has not been previously reported in HLB-affected trees. This GO category is well known to be altered in response to drought stress (Tian et al., 2015), phosphate deficiency (Park et al., 2012), ABA, and hydrogen peroxide stress (Kulik et al., 2011). Response to stress has previously been found to be a significant GO category in citrus varieties that are HLB tolerant (Wu et al., 2020). BIN 20 (stress) included DEGs related to biotic and abiotic stress. Within the biotic stress BIN, a high number of genes were related to PRprotein. PR-proteins are known to be upregulated in citrus when CLas is present (Zhong et al., 2015). MapMan analysis also revealed that 381 DEGs were involved in tree-pathogen/pest interaction. This group mainly included DEGs related to hormone, redox reaction, MYB family, WRKY family, proteolysis, and cell wall biotic stress. Similarly, Martinelli et al. (2012) and Zhong et al. (2015) reported several DEGs from this category expressed in HLB-affected root and leaf compared with their healthy counterparts. Fourteen upregulated DEGs were related to phenylpropanoid metabolic process, which encompassed secondary metabolic processes and the lignin metabolic process; secondary metabolism is well known to increase in response to CLas infection (Martinelli et al., 2012). Secondary metabolite production is a plant defense response to pathogen and oxidative stress (Isah, 2019). GO categories related to hormones, jasmonic acid-mediated signaling pathway, ethylene-mediated signaling pathway, and regulation of hormones were upregulated in HLB-F trees. An increase in jasmonic acid and ethylene as well as alteration in levels of major plant hormones has been widely reported in leaves upon CLas infection (Killiny et al., 2017; Martinelli et al., 2012; Rosales and Burns, 2011), potentially contributing to enhanced plant defense responses. Based on all the DEGs mentioned previously, it can be concluded that HLB-affected trees were undergoing a significant tree defense response. It should be noted that all the discussed genes were only differentially expressed on nutrient availability. This underlines the importance of nutrition to the trees. Nutrients not only help with growth and development but are also critical for tree defense response (Spann and Schumann, 2012).
Several GO categories were related to the development and cell death in HLB-F roots. Altogether this super GO group included 296 DEGs that were all downregulated. The GO categories included growth developmental processes, anatomic structure development, growth, cell cycle, meristem development, apoptosis, and cell death suggesting that the HLB-affected roots were undergoing significant root growth, development, and senescence process. It is known that HLB-affected trees undergo significant feeder root loss even if the feeder root growth (new growth) is found to be similar between healthy and HLB-affected trees (Johnson and Graham 2015; Johnson et al., 2014). Similarly, in the present study, the DEGs of GO categories related to meristem development, growth, and developmental processes as well as cell death and apoptosis were downregulated at the same time, which suggests that such events happen in HLB-affected trees grown under nutrient-available conditions. It can also be hypothesized that DEGs related to this super category increased the vascular bundle diameter to potentially improve the nutrient uptake.

Two other important GO categories observed were ion transport and response to nutrient levels. All 33 genes within these two categories were upregulated in HLB-F roots as compared with HLY-F roots. Both ion and anion transport categories are related to nutrient uptake in trees (Bi et al., 2014; Li et al., 2017; Zhu et al., 2019). In this study, HLB-F roots had a 2- to 3-fold higher nutrient uptake efficiency than HLY-F trees, suggesting that these three categories possibly contributed to increased nutrient uptake in HLB-F trees as compared with HLY-F.

Altogether, the results of transcriptomics suggest that the regulation of genes related to transport, growth, and development potentially improves the nutrient uptake in HLB-affected trees, but the small root biomass is a major limitation for HLBaffected trees. The availability of nutrients is also critical for both healthy and HLB-affected trees to carry out normal tree function, growth, development, and tree defense response. In nutrient-deficient conditions, many metabolic processes are presumably suppressed to conserve energy, which reduces growth. Healthy trees showed a high number of DEGs on transition from nutrient-deficient conditions to nutrient-available conditions compared with HLB-affected trees. This observation also suggests that, except for a handful of biotic stress-related genes, healthy and HLB-affected trees behave similarly under nutrient-deficient conditions. This underlines the importance of mineral nutrition in HLB-disease management and warrants further research.

\section{Conclusions}

The present greenhouse study is the first evaluation of nutrient uptake and its regulation in HLB-affected trees. HLB-affected trees experience nutrient deficiency that healthy trees do not when grown under similar nutrient conditions. HLB-affected roots are also functional and efficient in nutrient uptake; however, reduced biomass limits the nutrient uptake capacity of trees as a whole. To compensate for the reduced root-to-shoot ratio, the existing roots undergo anatomic and transcriptomic changes to improve nutrient uptake efficiency. It is possible that higher input of energy in nutrient uptake possibly results in reducing the root longevity of HLB-affected trees. Therefore, it is suggested that HLB-affected trees should be supplied with constant nutrients at higher rates than what is 
recommended for healthy trees. Such fertilization practices possibly mitigate the abiotic stress in HLB-affected trees. Good nutrition management practices are critical for the productivity of HLB-affected trees as the availability and uptake of nutrients allow HLB-affected trees to respond to abiotic and biotic stresses.

\section{Literature Cited}

Becraft, P.W. 2002. Receptor kinase signaling in plant development. Annu. Rev. Cell Dev. Biol. 18:163-192.

Bi, Y.M., A. Meyer, G.S. Downs, X. Shi, A. El-Kereamy, L. Lukens, and S.J. Rothstein. 2014. High throughput RNA sequencing of a hybrid maize and its parents shows different mechanisms responsive to nitrogen limitation. BMC Genomics 15:77.

Bové, J.M. 2006. Huanglongbing: A destructive, newly-emerging, century-old disease of citrus. J. Plant Pathol. 8:7-37.

Cakmak, I. and H. Marschner. 1992. Magnesium deficiency and high light intensity enhance activities of superoxide dismutase, ascorbate peroxidase, and glutathione reductase in bean leaves. Plant Physiol. 98:1222-1227.

Capaldi, F.R., P.L. Gratão, A.R. Reis, L.W. Lima, and R.A. Azevedo. 2015. Sulfur metabolism and stress defense responses in plants. Trop. Plant Biol. 8:60-73.

Chomczynski, P. and N. Sacchi. 1987. Single-step method of RNA isolation by acid guandinium thiocyanate-phenol chloroform extraction. Anal. Biochem. 162:156-159.

de Lorenzo, L., F. Merchan, P. Laporte, R. Thompson, J. Clarke, C. Sousa, and M. Crespi. 2009. A novel plant leucine-rich repeat receptor kinase regulates the response of Medicago truncatula roots to salt stress. Plant Cell 21:668-680.

Gaspar, T., C. Penel, and H. Greppin. 1992. Plant peroxidases, 19801990. A survey of their biochemical and physiological roles in higher plants. Univ. Geneva Press, Geneva, Switzerland.

Giles, F. 2011. Daring to be different. Florida Grower 104(6):8-10.

Gottwald, T.R., J.H. Graham, M.S. Irey, T.G. McCollum, and B.W. Wood. 2012. Inconsequential effect of nutritional treatments on Huanglongbing control, fruit quality, bacterial titer and disease progress. Crop Prot. 36:73-82.

Graham, J.H., E.G. Johnson, T.R. Gottwald, and M.S. Irey. 2013. Presymptomatic fibrous root decline in citrus trees caused by Huanglongbing and potential interaction with Phytophthora spp. Plant Dis. 97:1195-1199.

Greeff, C.C.G., M.M.R. Roux, J.J.M. Mundy, and M.M.P. Petersen. 2012. Receptor-like kinase complexes in plant innate immunity. Front. Plant Sci. 3:209.

Guerinot, M.L. and D. Eide. 1999. Zeroing in on zinc uptake in yeast and plants. Curr. Opin. Plant Biol. 2:244-249.

Halbert, S.E. and K.L. Manjunath. 2004. Asian citrus psyllids (Sternorrhyncha: Psyllidae) and greening disease of citrus: A literature review and assessment of risk in Florida. Fla. Entomol. 87:330 353.

Hall, B.P. and M.L. Guerinot. 2006. The role of ZIP family members in iron transport, p. 311-326. In: L.L. Barton and J. Abadía (eds.). Iron nutrition in plants and rhizospheric microorganisms. Springer, Dordrecht, The Netherlands.

Hamido, S.A., K. Morgan, R.C. Ebel, and D.M. Kadyampakeni. 2017a. Improved irrigation management of sweet orange with Huanglongbing. HortScience 52:916-921.

Hamido, S.A., K. Morgan, and D.M. Kadyampakeni. 2017b. The effect of Huanglongbing on young citrus tree water use. HortTechnology 27:659-665.

Isah, T. 2019. Stress and defense responses in plant secondary metabolites production. Biol. Res. 52:39.

Johnson, E.G. and J.H. Graham. 2015. Root health in the age of HLB. Citrus Ind. 96(8):14-18.

Johnson, E.G., J. Wu, D.B. Bright, and J.H. Graham. 2014. Association of "Candidatus Liberibacter asiaticus" root infection, but not phloem plugging with root loss on Huanglongbing-affected trees prior to appearance of foliar symptoms. Plant Pathol. 63: 290-298.

Kanehisa, M., M. Furumichi, M. Tanabe, Y. Sato, and K. Morishima. 2017. KEGG: New perspectives on genomes, pathways, diseases and drugs. Nucleic Acids Res. 45:D353-D361.

Killiny, N., M.F. Valim, S.E. Jones, A.A. Omar, F. Hijaz, F.G. Gmitter, and J.W. Grosser. 2017. Metabolically speaking: Possible reasons behind the tolerance of 'Sugar Belle' mandarin hybrid to Huanglongbing. Plant Physiol. Biochem. 116:36-47.

Kim, J.S., U.S. Sagaram, J.K. Burns, J.L. Li, and N. Wang. 2009. Response of sweet orange (Citrus sinensis) to 'Candidatus Liberibacter asiaticus' infection: Microscopy and microarray analyses. Phytopathology 99:50-57.

Krause, G.H. and E. Weis. 1991. Chlorophyll fluorescence and photosynthesis: The basics. Annu. Rev. Plant Biol. 42:313-349.

Kulik, A., I. Wawer, E. Krzywińska, M. Bucholc, and G. Dobrowolska. 2011. SnRK2 protein kinases-Key regulators of plant response to abiotic stresses. Omics J. Integ. Biol. 15:859-872.

Kusari, S., C. Hertweck, and M. Spiteller. 2012. Chemical ecology of endophytic fungi: Origins of secondary metabolites. Chem. Biol. 19:792-798.

Li, B. and C.N. Dewey. 2011. RSEM: Accurate transcript quantification from RNA-Seq data with or without a reference genome. BMC Bioinformatics 12:323.

Li, Y., J. Huang, X. Song, Z. Zhang, Y. Jiang, Y. Zhu, H. Zhao, and D. Ni. 2017. An RNA-Seq transcriptome analysis revealing novel insights into aluminum tolerance and accumulation in tea plant. Planta 246:91-103.

Lin, Y., H. Liang, S. Yang, A. Boch, S. Clemens, C. Chen, J. Wu, J. Huang, and K. Yeh. 2009. Arabidopsis IRT3 is a zinc-regulated and plasma membrane localized zinc/iron transporter. New Phytol. 182:392-404.

Martinelli, F., S.L. Uratsu, U. Albrecht, R.L. Reagan, M.L. Phu, M. Britton, V. Buffalo, J. Fass, E. Leicht, W. Zhao, D. Lin, R. D’Souza, C.E. Davis, K.D. Bowman, and A.M. Dandekar. 2012. Transcriptome profiling of citrus fruit response to Huanglongbing disease. PLoS One 7:e38039.

Morgan, K.T. and J.H. Graham. 2019. Nutrient status and root density of Huanglongbing-affected trees: Consequences of irrigation water bicarbonate and soil $\mathrm{pH}$ mitigation with acidification. Agronomy 9:746.

Morgan, K.T., R.E. Rouse, and R.C. Ebel. 2016. Foliar applications of essential nutrients on growth and yield of 'Valencia' sweet orange infected with Huanglongbing. HortScience 51:1482-1493.

Obreza, T.A. and K.T. Morgan. 2008. Nutrition of Florida citrus trees. 2nd ed. Univ. Florida, Inst. Food Agr. Sci. Ext. SL253. 20 Jan. 2020. $<$ https://edis.ifas.ufl.edu/ss478>.

Pandey, V., A. Patel, and D.D. Patra. 2015. Amelioration of mineral nutrition, productivity, antioxidant activity and aroma profile in marigold (Tagetes minuta L.) with organic and chemical fertilization. Ind. Crops Prod. 76:378-385.

Park, M.R., S.H. Baek, G. Benildo, S.J. Yun, and K.H. Hasenstein. 2012. Transcriptome profiling characterizes phosphate deficiency effects on carbohydrate metabolism in rice leaves. J. Plant Physiol. 169:193-205.

Rio, D.C. 2015. Denaturation and electrophoresis of RNA with formaldehyde. Cold Spring Harb. Protoc. 2015:306-313.

Romheld, V. and H. Marschner. 1991. Function of micronutrients in plants, p. 297-328. In: J.J. Mortvedt, F.R. Cox, L.M. Shuman, and R.M. Welch (eds.). Micronutrients in agriculture. Soil Sci. Soc. Amer., Madison, WI.

Rosales, R. and J. Burns. 2011. Phytohormone changes and carbohydrate status in sweet orange fruit from Huanglongbing-infected trees. J. Plant Growth Regul. 30:312-321.

Rouse, R.E., M. Ozores-Hampton, F.M. Roka, and P. Roberts. 2017. Rehabilitation of Huanglongbing-affected citrus trees using severe pruning and enhanced foliar nutritional treatments. HortScience 52:972-978. 
Ruzin, S.E. 1999. Plant microtechnique and microscopy. Oxford Univ. Press, New York, NY.

Sasek, T.W., E.H. Delucia, and B.R. Strain. 1985. Reversibility of photosynthetic inhibition in cotton after long-term exposure to elevated $\mathrm{CO}_{2}$ concentrations. Plant Physiol. 78:619-622.

Scheible, W.R., R. Morcuende, T. Czechowski, C. Fritz, D. Osuna, N. Palacios-Rojas, D. Schindelasch, O. Thimm, M.K. Udvardi, and M. Stitt. 2004. Genome-wide reprogramming of primary and secondary metabolism, protein synthesis, cellular growth processes, and the regulatory infrastructure of Arabidopsis in response to nitrogen. Plant Physiol. 136:2483-2499.

Schindelin, J., I. Arganda-Carreras, E. Frise, V. Kaynig, M. Longair, T. Pietzsch, S. Preibisch, C. Rueden, S. Saalfeld, B. Schmid, and J.Y. Tinevez. 2012. Fiji: An open-source platform for biological-image analysis. Nat. Methods 9:676-682.

Schneider, H. 1968. Anatomy of greening-diseased sweet orange shoots. Phytopathology 58:1155-1160.

Singerman, A. and P. Useche. 2016. Impact of citrus greening on citrus operations in Florida. Univ. Florida, Inst. Food. Agr. Sci. FE983. 29 May 2020. <https://edis.ifas.ufl.edu/fe983>.

Spann, T.M. and A.W. Schumann. 2012. Using good horticultural practices to maintain yield of HLB-affected groves. Citrus Ind. 93(6):6-11.

Supek, F., M. Bošnjak, N. Škunca, and T. Šmuc. 2011. REVIGO summarizes and visualizes long lists of gene ontology terms. PLoS One 6:e21800.

Tang, L., S. Chhajed, and T. Vashisth. 2019. Preharvest fruit drop in Huanglongbing-affected 'Valencia' sweet orange. J. Amer. Soc. Hort. Sci. 144:107-117.

Tang, L. and T. Vashisth. 2020. New insight in Huanglongbingassociated mature fruit drop in citrus and its link to oxidative stress. Scientia Hort. 265:109246.

Thimm, O., O. Bläsing, Y. Gibon, A. Nagel, S. Meyer, P. Krüger, J. Selbig, L.A. Müller, S.Y. Rhee, and M. Stitt. 2004. MAPMAN: A userdriven tool to display genomics data sets onto diagrams of metabolic pathways and other biological processes. Plant J. 37:914-939.

Tian, T., Y. Liu, H. Yan, Q. You, X. Yi, Z. Du, W. Xu, and Z. Su. 2017. agriGO v2. 0: A GO analysis toolkit for the agricultural community, 2017 update. Nucleic Acids Res. 45:W122-W129.

Tian, X., Y. Long, J. Wang, J. Zhang, Y. Wang, W. Li, Y. Peng, Q. Yuan, and X. Pei. 2015. De novo transcriptome assembly of common wild rice (Oryza rufipogon Griff.) and discovery of drought-response genes in root tissue based on transcriptomic data. PLoS One 10:e0131455.

Tör, M., M.T. Lotze, and N. Holton. 2009. Receptor-mediated signalling in plants: Molecular patterns and programmes. J. Expt. Bot. 60:3645-3654.

U.S. Department of Agriculture. 2019. Florida citrus statistics 2018/ 2019. U.S. Dept. Agr., Washington, DC.

Usadel, B., A. Nagel, O. Thimm, H. Redestig, O.E. Blaesing, N. PalaciosRojas, J. Selbig, J. Hannemann, M.C. Piques, and D. Steinhauser. 2005.
Extension of the visualization tool MapMan to allow statistical analysis of arrays, display of corresponding genes, and comparison with known responses. Plant Physiol. 138:1195-1204.

Vashisth, T. 2020. Nutrition: No one size fits all. Citrus Ind. 101(2):8-13. Vashisth, T. and T. Livingston. 2019. Assessment of pruning and controlled-release fertilizer to rejuvenate Huanglongbing-affected sweet orange. HortTechnology 29:933-940.

Vashisth, T. and T. Livingston. 2020. Efficacy of in-field thermotherapy in comparison and combination of defoliation for mitigating Huanglongbing in sweet orange. HortScience 55:251-257.

Vashisth, T. and C. Vincent. 2018. Living with yellow dragon disease. Citrus Ind. 99(3):10-13.

Wiermer, M., B.J. Feys, and J.E. Parker. 2005. Plant immunity: The EDSi regulatory node. Curr. Opin. Plant Biol. 8:383-389.

Wu, G.A., S. Prochnik, J. Jenkins, J. Salse, U. Hellsten, F. Murat, X. Perrier, M. Ruiz, S. Scalabrin, J. Terol, M.A. Takita, K. Labadie, J. Poulain, A. Couloux, K. Jabbari, F. Cattonaro, C. Del Fabbro, S. Pinosio, A. Zuccolo, J. Chapman, J. Grimwood, F.R. Tadeo, L.H. Estornell, J.V. Muñoz-Sanz, V. Ibanez, A. Herrero-Ortega, P. Aleza, J. Pérez-Pérez, D. Ramón, D. Brunel, F. Luro, C. Chen, W.G. Farmerie, B. Desany, C. Kodira, M. Mohiuddin, T. Harkins, K. Fredrikson, P. Burns, A. Lomsadze, M. Borodovsky, G. Reforgiato, J. Freitas-Astúa, F. Quetier, L. Navarro, M. Roose, P. Wincker, J. Schmutz, M. Morgante, M.A. Machado, M. Talon, O. Jaillon, P. Ollitrault, F. Gmitter, and D. Rokhsar. 2014. Sequencing of diverse mandarin, pummelo and orange genomes reveals complex history of admixture during citrus domestication. Nat. Biotechnol. 32:656-662. Wu, H., Y. Hu, S. Fu, C. Zhou, and X. Wang. 2020. Coordination of multiple regulation pathways contributes to the tolerance of a wild citrus species (Citrus ichangensis '2586') against Huanglongbing. Physiol. Mol. Plant Pathol. 109:101457.

Yelle, S., R.C. Beeson, Jr., M.J. Trudel, and A. Gosselin. 1989. Acclimation of two tomato species to high atmospheric $\mathrm{CO}_{2}$. II. ribulose-1, 5-bisphosphate carboxylase/oxygenase and phosphoeno/ pyruvate carboxylase. Plant Physiol. 1:1473-1477.

Zambon, F.T., D.M. Kadyampakeni, and J.W. Grosser. 2019. Ground application of overdoses of manganese have a therapeutic effect on sweet orange trees infected with Candidatus Liberibacter asiaticus. HortScience 54:1077-1086.

Zekri, M. and R.C.J. Koo. 1991. Evaluation of controlled-release fertilizers for young citrus trees. J. Amer. Soc. Hort. Sci. 116:987-990. Zhong, Y., C. Cheng, N. Jiang, B. Jiang, Y. Zhang, B. Wu, M. Hu, J. Zeng, H. Yan, and G. Yi. 2015. Comparative transcriptome and ITRAQ proteome analyses of citrus root responses to Candidatus Liberibacter asiaticus infection. PLoS One 10:e0126973.

Zhu, Y., J. Yin, Y. Liang, J. Liu, J. Jia, H. Huo, Z. Wu, R. Yang, and H. Gong. 2019. Transcriptomic dynamics provide an insight into the mechanism for silicon-mediated alleviation of salt stress in cucumber plants. Ecotoxicol. Environ. Saf. 174:245-254. 


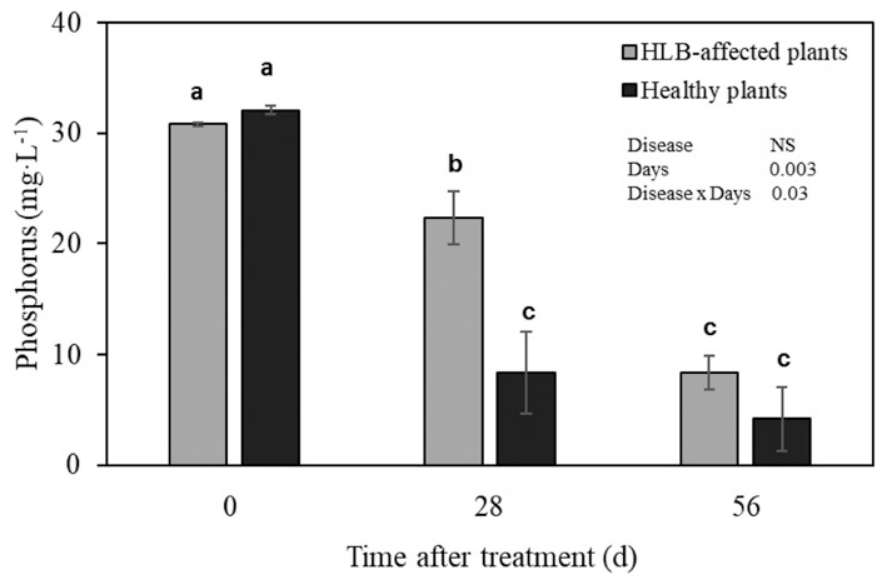

Supplemental Fig. 1. Phosphorus content in the hydroponic solution of Huanglongbing (HLB)-affected and healthy sweet orange trees grown in hydroponic system with fertilizer solution for $56 \mathrm{~d}$. Fertilizer solution was added on day 0 of the experiment. The P content in solution indicates the amount of $\mathrm{P}$ uptake in the plant, higher the $\mathrm{P}$ content in solution, lower is the uptake by plant. Different letters over each bar indicate significant difference based on Tukey's honestly significant difference test $(\alpha=0.05)$; NS $=$ not significantly different.

Polypropanoid biosynthesis process

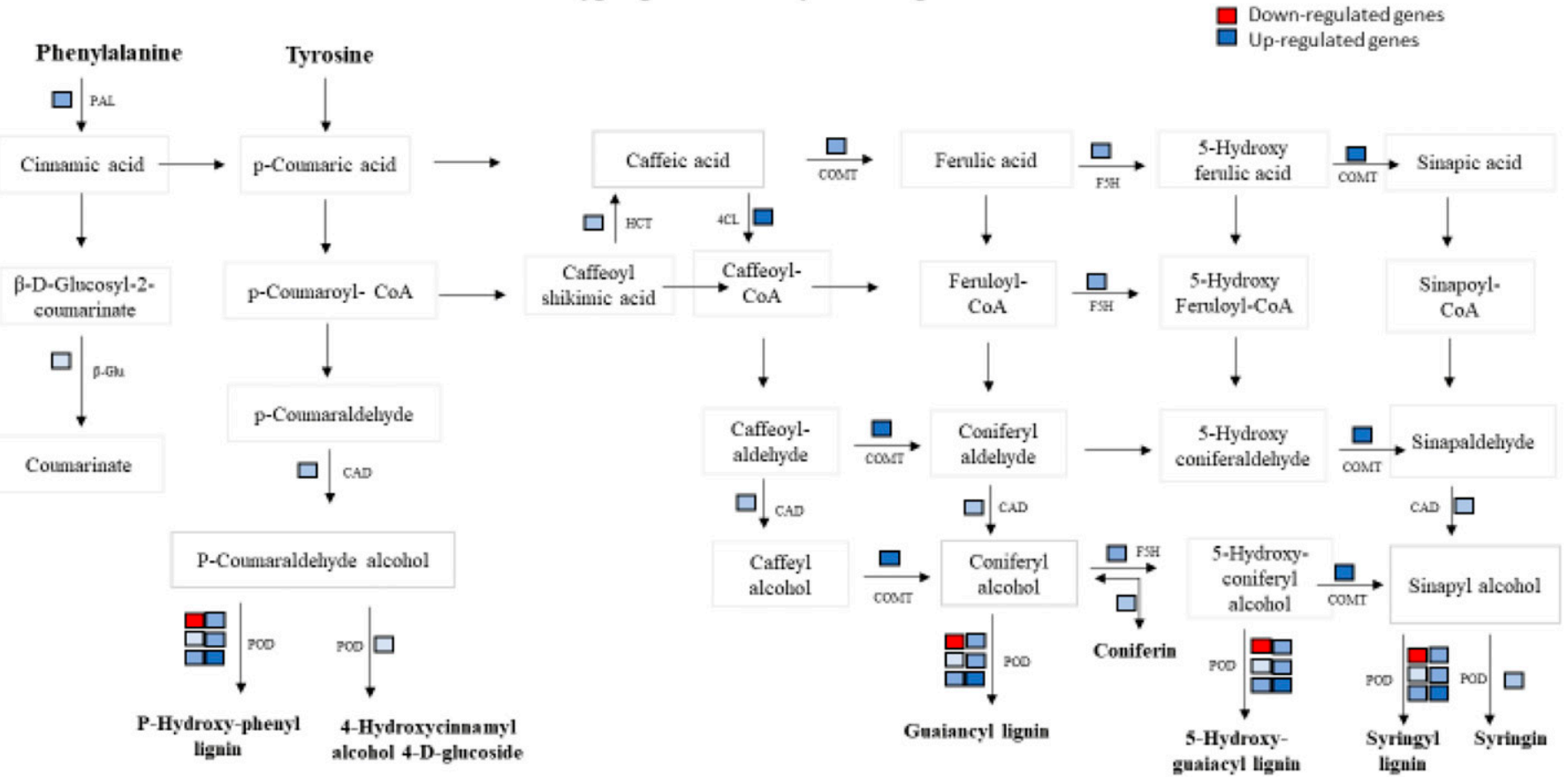

Supplemental Fig. 2. Overview of the phenylpropanoid pathway-related differentially expressed genes in Huanglongbing (HLB)-affected compared with healthy sweet orange trees on day 9 since the addition of fertilizer solution. Red and blue indicating downregulated and upregulated genes in HLB-affected trees, respectively. 
Supplemental Table 1. List of genes along with gene-specific primer sequences used for relative gene expression analysis in feeder roots of Huanglongbing-affected and healthy sweet orange trees.

\begin{tabular}{|c|c|c|c|c|}
\hline Description (gene symbol) & Gene & $\begin{array}{c}\text { GenBank } \\
\text { accession no. }\end{array}$ & $\begin{array}{c}\text { Forward and reverse } \\
\text { primer sequences }\left(5^{\prime} \text { to } 3^{\prime}\right)\end{array}$ & $\begin{array}{l}\text { Amplicon size } \\
\text { (base pairs) }\end{array}$ \\
\hline \multirow[t]{2}{*}{ senescence-associated gene 20 (SAG20) } & \multirow[t]{2}{*}{ orange 1.1g041268m } & \multirow[t]{2}{*}{ XM_006486163.3 } & AAAGCCATCACCAGTTCTC & \multirow[t]{2}{*}{117} \\
\hline & & & GTTCTTGACGGAATAGCCTTA & \\
\hline \multirow[t]{2}{*}{ ethylene response factor 1 (ERF 1$)$} & \multirow[t]{2}{*}{ orange1.1g042174m } & \multirow[t]{2}{*}{ XM_006477063.3 } & ACG TAG CGC TTC TCA AAC CC & \multirow[t]{2}{*}{136} \\
\hline & & & GCC AAT GAC CAC GAT GTT GA & \\
\hline \multirow{2}{*}{$\begin{array}{l}\text { 2-oxoglutarate and } \mathrm{Fe} \text { dependent } \\
\text { oxygenase superfamily protein } \\
(2 \mathrm{OG}-\mathrm{Fe})\end{array}$} & \multirow[t]{2}{*}{ orange1.1g039524m } & \multirow[t]{2}{*}{ XM_006490040.2 } & GGACTTGACGAACGTTGCTT & \multirow[t]{2}{*}{143} \\
\hline & & & ATCAAGCAGCATGAAGCTTTG & \\
\hline \multirow[t]{2}{*}{ auxin-responsive family protein $(A B F 3)$} & \multirow[t]{2}{*}{ orange1.1g041715m } & \multirow[t]{2}{*}{ XM_006487050.3 } & AGCGGTGCTCTGGAGAAAG & \multirow[t]{2}{*}{168} \\
\hline & & & СТCTGCCTGTTTCCTCTCCAA & \\
\hline \multirow[t]{2}{*}{ zinc transporter 10 precursor (ZIP10) } & \multirow[t]{2}{*}{ orange $1.1 \mathrm{~g} 018585 \mathrm{~m}$} & \multirow[t]{2}{*}{ XM_006481314.3 } & CTATCGGGACTCTGATGATT & \multirow[t]{2}{*}{113} \\
\hline & & & СССААСТТТСТСТТСАТСТG & \\
\hline \multirow[t]{2}{*}{ calcium dependent calmodulin (CAM8) } & \multirow[t]{2}{*}{ orange1.1g031903m } & \multirow[t]{2}{*}{ XM_006489415.3 } & TGACGCTGAGGAAGAGCTTAAA & \multirow[t]{2}{*}{163} \\
\hline & & & ATCACCGTCCAAATCAGCCTC & \\
\hline \multirow[t]{2}{*}{$\operatorname{actin}-7(A C T)$} & \multirow[t]{2}{*}{$\mathrm{n} / \mathrm{a}$} & \multirow[t]{2}{*}{ XM_006464503.2 } & GTTGGTTGACATGGAGAAG & \multirow[t]{2}{*}{121} \\
\hline & & & ACGGTTGAGTACAGAAATAAG & \\
\hline \multirow[t]{2}{*}{ thioredoxin-like protein YLS8 (DIM1) } & \multirow[t]{2}{*}{$\mathrm{n} / \mathrm{a}$} & \multirow[t]{2}{*}{ XM_006484463.2 } & CGAAACCTGTATGCAGATGG & \multirow[t]{2}{*}{138} \\
\hline & & & ACGGTTGAGGGATCGTAAAG & \\
\hline
\end{tabular}

Supplemental Table 2. Differentially expressed genes categorized in the functional categories (BINs) related to hormone metabolism and signaling according to MapMan analysis (Thimm et al., 2004; Usadel et al., 2005) with respective Arabidopsis homologs and $\log _{2}$ fold change (LFC) in Huanglongbing (HLB)-affected sweet orange trees in comparison with healthy sweet orange trees on day 9 after the addition of Hoagland (fertilizer) solution.

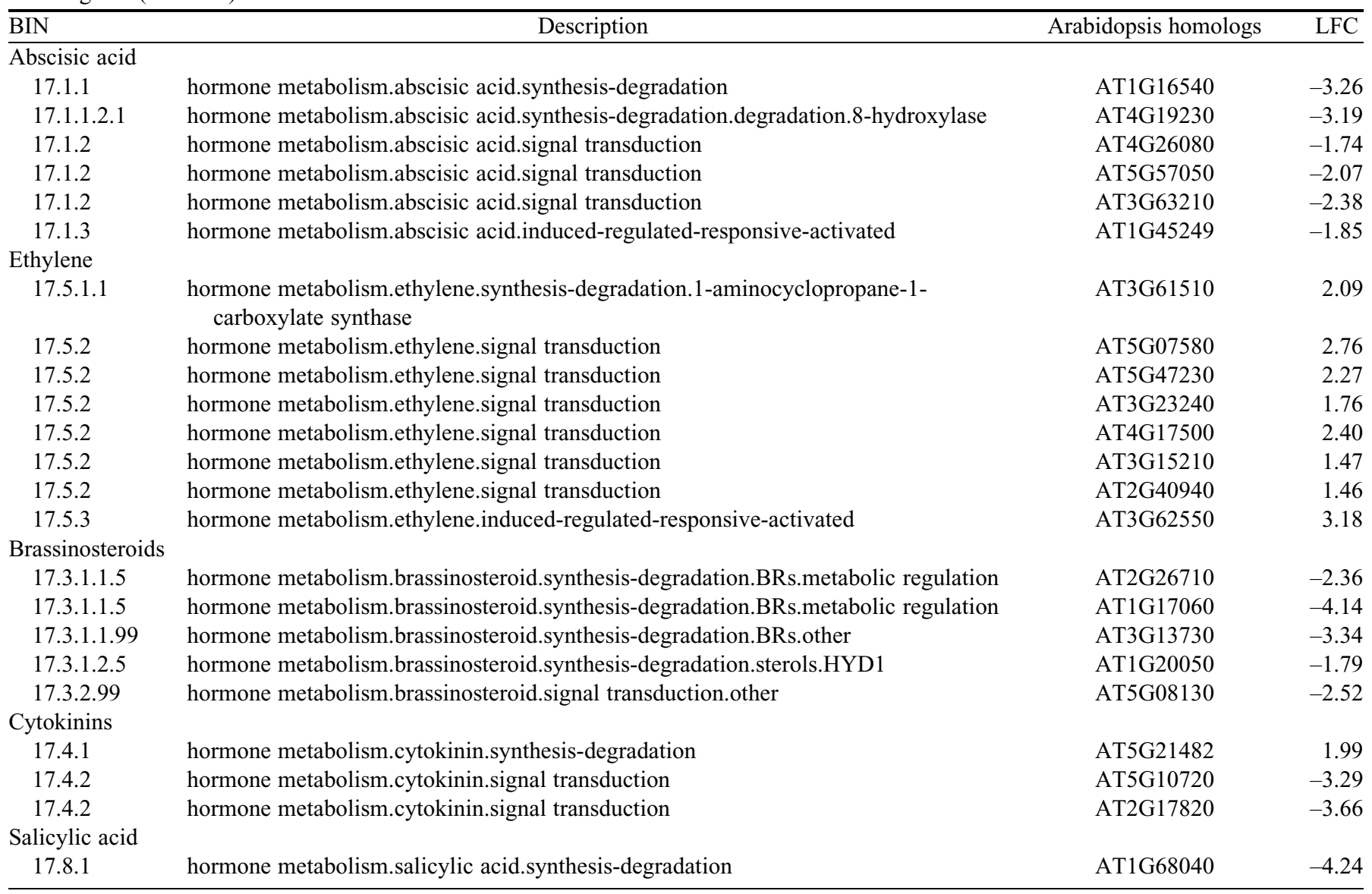


Supplemental Table 3. Differentially expressed genes categorized in the functional categories (BINs) related to plant-pathogen/pest interaction according to MapMan analysis (Thimm et al., 2004; Usadel et al., 2005) with respective Arabidopsis homologs and $\log _{2}$ fold change (LFC) in Huanglongbing (HLB)-affected sweet orange trees in comparison with healthy sweet orange trees on day 9 since the addition of Hoagland (fertilizer) solution.

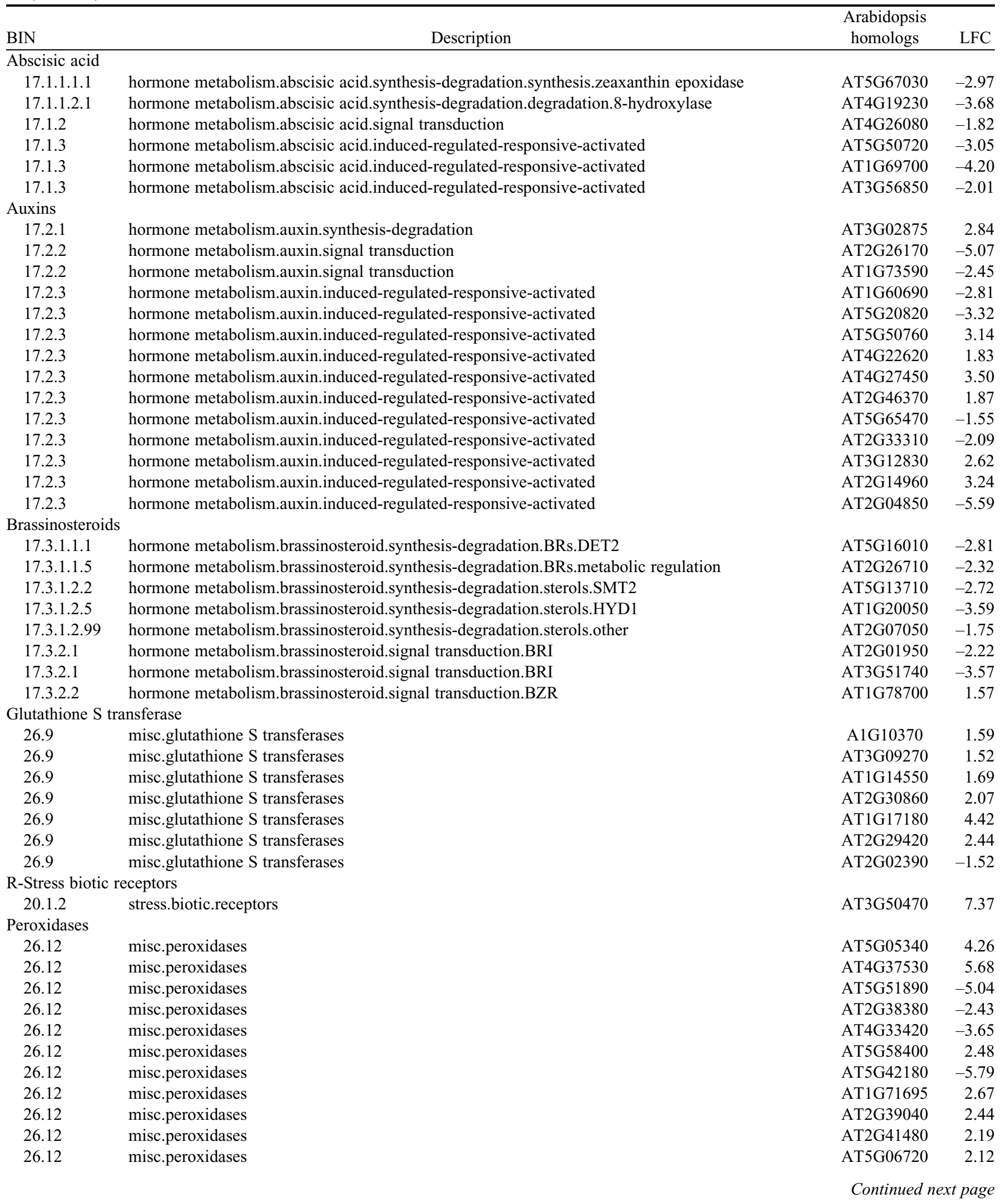




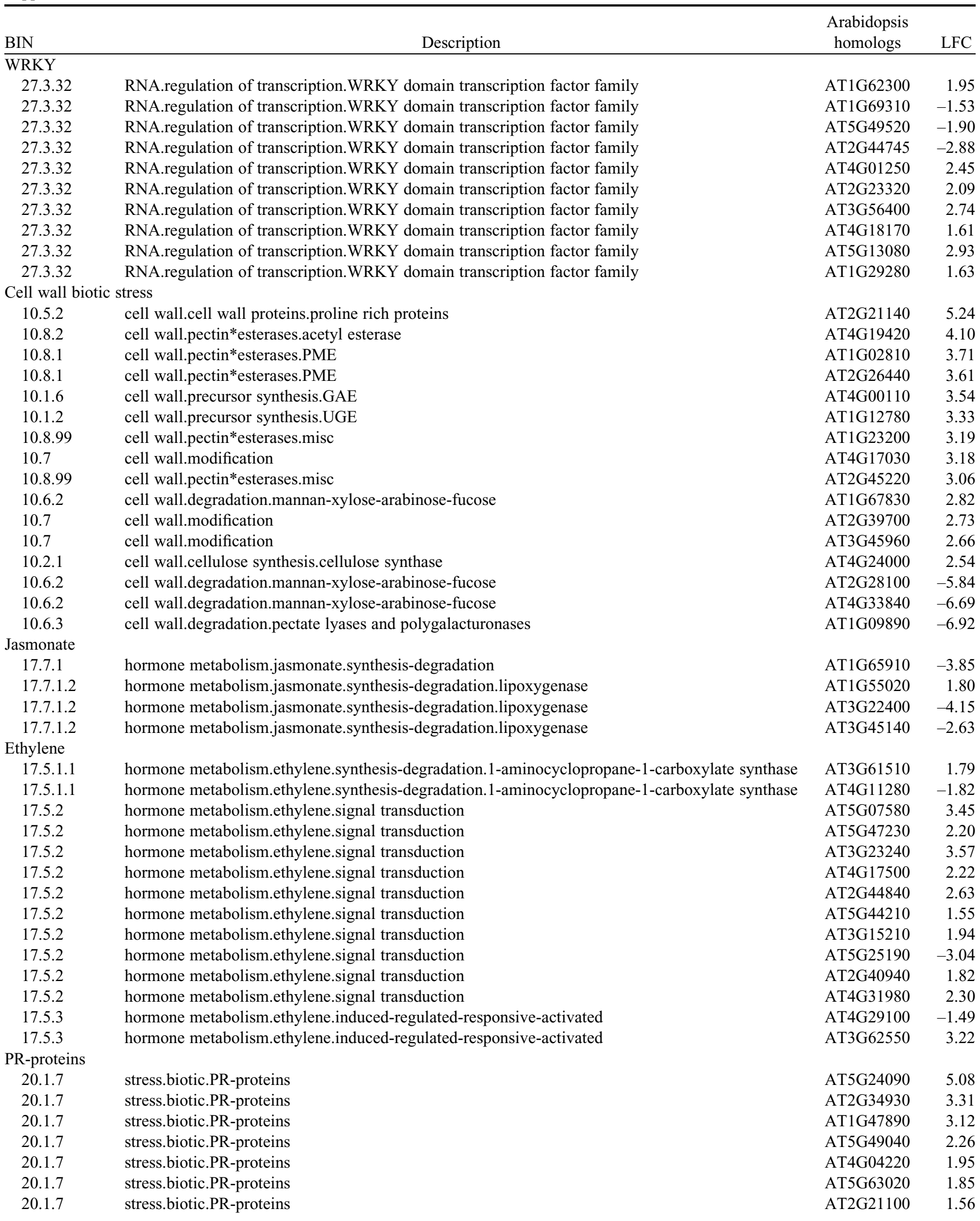




\begin{tabular}{|c|c|c|c|}
\hline BIN & Description & $\begin{array}{c}\text { Arabidopsis } \\
\text { homologs }\end{array}$ & LFC \\
\hline 20.1 .7 & stress.biotic.PR-proteins & AT5G23400 & -2.06 \\
\hline 20.1 .7 & stress.biotic.PR-proteins & AT5G36930 & -2.49 \\
\hline 20.1 .7 & stress.biotic.PR-proteins & AT1G69550 & -3.95 \\
\hline 20.1 .7 & stress.biotic.PR-proteins & AT5G17680 & -4.07 \\
\hline 20.1.7.6.1 & stress.biotic.PR-proteins.proteinase inhibitors.trypsin inhibitor & AT1G17860 & -9.99 \\
\hline \multicolumn{4}{|l|}{ Salicylic acid } \\
\hline 17.8.1 & hormone metabolism.salicylic acid.synthesis-degradation & AT1G68040 & -6.42 \\
\hline 17.8 .1 & hormone metabolism.salicylic acid.synthesis-degradation & AT3G11480 & -4.71 \\
\hline 17.8 .1 & hormone metabolism.salicylic acid.synthesis-degradation & AT5G66430 & 2.19 \\
\hline 27.3 .25 & RNA.regulation of transcription.MYB domain transcription factor family & AT3G46130 & -4.59 \\
\hline 27.3 .25 & RNA.regulation of transcription.MYB domain transcription factor family & AT5G52600 & -4.04 \\
\hline 27.3 .25 & RNA.regulation of transcription.MYB domain transcription factor family & AT5G42630 & -3.27 \\
\hline 27.3 .25 & RNA.regulation of transcription.MYB domain transcription factor family & AT2G02820 & -3.12 \\
\hline
\end{tabular}


Supplemental Table 4. Differentially expressed genes categorized in the functional categories (BINs) related to cell wall modification according to MapMan analysis (Thimm et al., 2004; Usadel et al., 2005) with Arabidopsis homologs, and $\log _{2}$ fold change (LFC) in Huanglongbingaffected sweet orange trees in comparison with healthy sweet orange trees on day 9 since the addition of fertilizer solution.

\begin{tabular}{|c|c|c|c|}
\hline $\mathrm{BIN}$ & Description & Arabidopsis homologs & LFC \\
\hline 10.1 .6 & cell wall.precursor synthesis.GAE & At4G00110 & 3.59 \\
\hline 10.6 .2 & cell wall.degradation.mannan-xylose-arabinose-fucose & AT5G49360 & 3.20 \\
\hline 10.6 .2 & cell wall.degradation.mannan-xylose-arabinose-fucose & AT1G02640 & 2.66 \\
\hline 10.1 .2 & cell wall.precursor synthesis.UGE & AT1G12780 & 2.45 \\
\hline 10.2 .1 & cell wall.cellulose synthesis.cellulose synthase & AT4G24000 & 2.41 \\
\hline 10.6 .3 & cell wall.degradation.pectate lyases and polygalacturonases & AT1G09910 & -2.01 \\
\hline 10.1 .9 & cell wall.precursor synthesis.MUR4 & AT1G30620 & -2.05 \\
\hline 10.8 .1 & cell wall.pectin*esterases.PME & AT1G53840 & -2.06 \\
\hline 10.2 .2 & cell wall.cellulose synthesis.COBRA & AT5G60920 & -2.10 \\
\hline 10.3 & cell wall.hemicellulose synthesis & AT3G45400 & -2.12 \\
\hline 10.8 .99 & cell wall.pectin*esterases.misc & AT2G45220 & -2.55 \\
\hline 10.6 .3 & cell wall.degradation.pectate lyases and polygalacturonases & AT1G09890 & -2.99 \\
\hline 10.6.3 & cell wall.degradation.pectate lyases and polygalacturonases & AT4G33440 & -3.13 \\
\hline 10.6 .3 & cell wall.degradation.pectate lyases and polygalacturonases & AT5G14650 & -4.46 \\
\hline 10.5.1 & cell wall.cell wall proteins.AGPs & AT5G06390 & -4.89 \\
\hline 10.8 .99 & cell wall.pectin*esterases.misc & AT4G02330 & -7.28 \\
\hline
\end{tabular}

